\title{
Alteration in circulating metabolites during and after heat stress in the conscious rat: potential biomarkers of exposure and organ-specific injury
}

\author{
Danielle L Ippolito ${ }^{1}$, John A Lewis ${ }^{1}$, Chenggang $\mathrm{Yu}^{2}$, Lisa R Leon ${ }^{3}$ and Jonathan D Stallings ${ }^{\text {** }}$
}

\begin{abstract}
Background: Heat illness is a debilitating and potentially life-threatening condition. Limited data are available to identify individuals with heat illness at greatest risk for organ damage. We recently described the transcriptomic and proteomic responses to heat injury and recovery in multiple organs in an in vivo model of conscious rats heated to a maximum core temperature of $41.8^{\circ} \mathrm{C}\left(T_{C, M a x}\right)$. In this study, we examined changes in plasma metabolic networks at $T_{C, M a x}, 24$, or 48 hours after the heat stress stimulus.

Results: Circulating metabolites were identified by gas chromatography/mass spectrometry and liquid chromatography/tandem mass spectrometry. Bioinformatics analysis of the metabolomic data corroborated proteomics and transcriptomics data in the tissue at the pathway level, supporting modulations in metabolic networks including cell death or catabolism (pyrimidine and purine degradation, acetylation, sulfation, redox alterations and glutathione metabolism, and the urea cycle/creatinine metabolism), energetics (stasis in glycolysis and tricarboxylic acid cycle, $\beta$-oxidation), cholesterol and nitric oxide metabolism, and bile acids. Hierarchical clustering identified 15 biochemicals that differentiated animals with histopathological evidence of cardiac injury at 48 hours from uninjured animals. The metabolic networks perturbed in the plasma corroborated the tissue proteomics and transcriptomics pathway data, supporting a model of irreversible cell death and decrements in energetics as key indicators of cardiac damage in response to heat stress.
\end{abstract}

Conclusions: Integrating plasma metabolomics with tissue proteomics and transcriptomics supports a diagnostic approach to assessing individual susceptibility to organ injury and predicting recovery after heat stress.

Keywords: Heat stress, Metabolomics, Systems biology, Energetics, Metabolic networks

\section{Background}

Heat illness and heat stroke, the most severe form of heat illness, are life-threatening conditions characterized by elevations in core temperature $\left(\mathrm{T}_{\mathrm{c}}\right)$ resulting from an inability to adequately dissipate excess body heat to the environment. The intrinsic nature of military operations (i.e., heavy physical activity in extreme environments) places military personnel at greater risk of developing heat-related illnesses. Sustained military operations in the Middle East have been accompanied by an increase in the number of heat stroke cases on the battlefield and

\footnotetext{
* Correspondence: jonathan.d.stallings.mil@mail.mil

${ }^{1}$ The United States Army Center for Environmental Health Research, Environmental Health Program, Bldg. 568 Doughten Drive, Fort Detrick, Frederick, MD 21702-5010, USA

Full list of author information is available at the end of the article
}

in training. During the past two decades alone the incidence of heat stroke has increased over seven-fold [1]. Moreover, the 30-year mortality rates from heart, kidney, and liver failure in US forces increases by $40 \%$ in individuals with a history of heat stroke [2,3]. In 2013, US forces sustained over 2000 heat-related injuries requiring hospitalization, including 324 cases of heat stroke [1]. The actual incidence is projected to be considerably higher when considering undocumented instances that never reach triage [4,5]. In a five-year retrospective study, 10,319 cases of heat injury required medical resources to treat, including 1872 cases of heat stroke [4]. The estimated cost to the military approaches $\$ 52$ million per year (USD), assuming a cost of $\$ 6200$ per

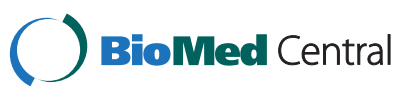

(c) 2014 Ippolito et al.; licensee BioMed Central. This is an Open Access article distributed under the terms of the Creative Commons Attribution License (http://creativecommons.org/licenses/by/4.0), which permits unrestricted use, distribution, and reproduction in any medium, provided the original work is properly credited. The Creative Commons Public Domain Dedication waiver (http://creativecommons.org/publicdomain/zero/1.0/) applies to the data made available in this article, unless otherwise stated. 
day, an average hospital stay of 3.2 days, and 2620 cases of heat injuries and heat stroke per year [6]. Other costs include duty days and salary lost during recovery (up to 5.5 months) and the loss in investment and training associated with service discharge for medical reasons [6]. Taken together, these statistics indicate that there is an urgent need for earlier indicators of organ injury and susceptibility and molecular based indicators to improve return to duty decisions [7].

The physiological responses to an excess heat load include elevations in heart rate, a drop in mean arterial pressure, attenuated sweating rates, stupor, and collapse. The molecular level alterations and influence of the physiological events preceding and contributing to the systemic inflammatory response associated with heat stroke remain largely unknown. Heat stroke compromises tight junction integrity in the gut, resulting in leakage of bacteria into the circulation [8]. If uncontrolled, the ensuing thermoregulatory and immune responses can progress to system inflammatory response syndrome (SIRS) and ultimately multi-organ failure and death [9-13]. Designing novel and effective treatment and detection strategies for heat stroke requires a better understanding of the physiological and molecular alterations that accompany heat stroke and characterize the SIRS event. However, in human studies $39.0-39.5^{\circ} \mathrm{C}$ is the highest ethically attainable maximal core temperature $\left(\mathrm{T}_{\mathrm{c}, \mathrm{Max}}\right)$, but these temperatures are insufficient to induce heat stroke. To overcome these ethical limitations, we recently described conscious rat and mouse models of heat illness [10,11,14-18]. The models use abdominally implanted radiotelemetry units to track $T_{c}$ while supporting physiological and behavioral adjustments to heat stress. In a recent study, we used our physiological model of heat stress to conduct an integrated systems biology evaluation of transcriptomic and proteomic changes in heart, liver, kidney, and lung after heat stress, heat injury, and recovery [19]. We identified discriminatory gene and protein signatures in heat-injured cardiac tissue reflecting perturbations in oxidative phosphorylation, energy production, and inflammatory response.

These global changes in metabolic networks associated with energy production in target tissues suggest that more accessible biofluids (e.g., serum, plasma, urine, and saliva) are also likely to reflect changes in the physiological state of the heat-stressed and heat-injured organism. Metabolomic profiling of plasma in conjunction with proteomic and transcriptomic analysis has recently emerged as a powerful predictive tool reflecting the dynamic responses to genetic modification and physiological, pathophysioloigcal, and/or developmental stimuli. However, perturbation in metabolic networks has not been well studied in heat illness. Understanding the metabolic response to heat illness and subsequent organ injury provides unique insight into understanding how mammalian systems react to heat illness and recovery. Further, methods to interrogate metabolites in accessible biofluids have been developed to allow a global assessment of organism response to environmental stressors [20]. One disadvantage of metabolomics is the likelihood of false positives given the metabolome's exquisite sensitivity to subtle changes in physiology (e.g., food intake, changes in temperature, stress, etc.). Therefore, any study of the metabolome must discriminate pathological changes in metabolic networks from changes inherent in normal physiological functioning. Integrating metabolic networks at the level of molecular function is one approach to differentiate changes related to heat-stress and/or heat-injury from physiological variation in the unperturbed system. Bioinformatics methods can be used to identify an integrated panel of multiple physiological networks and biomarkers.

In this study, we evaluate the metabolomic profile in response to heat stress and heat injury, and compare the results with the proteomic and transcriptomic profiles described previously. We demonstrate plasma metabolomics profiles unique to the physiological conditions of heat stress, heat injury in cardiac tissue, and heat stress without injury. Metabolomics network analysis demonstrates perturbations in biological processes associated with energy usage and cell death, similar to the transcriptomics and proteomics analyses conducted previously. Further, integrated analysis of variance (ANOVA) analysis, random forest analysis, and hierarchical clustering analysis identify panels of biochemicals differentiating controls from heat-stressed and heat-injured animals.

\section{Results and discussion}

\section{Thermoregulation and histopathology}

$\mathrm{T}_{\mathrm{c}, \mathrm{Max}}$ was reached at 2-3 hours, as previously published by our laboratories in more detailed thermoregulation analyses conducted with these animals and other similar studies [19,21]. Animals in the 24 and 48 hour cohorts were allowed to recover for the specified time prior to termination. In thermoregulation studies with these animals, temperatures return to baseline by $24-48$ hours, but cardiac-injured animals exhibit hypothermia before recovery, as published in detail by our laboratory [19].

Liver, kidney, and heart were assessed by histopathology and scored for evidence of injury as described previously [19]. The heart was the only tissue with treatmentrelated evidence for injury, with inflammation and cardiomyopathy in three out of six animals in the heated cohort as described in detail in a recent publication from our laboratory [19] (Additional file 1A). For the remainder of the study, animals in the 48 hour treatment group were sub-stratified into cohorts according to uninjured vs. injured. 
The metabolomics heat stress response and recovery in plasma-biochemical networks Overview of metabolic network changes

A total of 422 biochemicals were identified that matched 307 named/identified chemicals in Metabolon's reference library, with 115 unidentified biochemicals (Additional file 1). The largest change in number of biochemicals relative to controls occurred at $\mathrm{T}_{\mathrm{c}, \mathrm{Max}}$, with fewer alterations at 24 and 48 hours. The key biochemicals represented pathways related to the following categories: cell death or catabolism (pyrimidine and purine degradation, acetylation, sulfation, redox alterations and glutathione metabolism, and the urea cycle/creatinine metabolism), energetics (stasis in glycolysis and tricarboxylic acid [TCA] cycle, $\beta$-oxidation), cholesterol and nitric oxide metabolism, and bile acids (Figure 1).

$\mathrm{T}_{\mathrm{c}, \text { Max }}$ showed the greatest percentage of biochemicals altered in response to heat injury in virtually all categories. At $\mathrm{T}_{\mathrm{c}, \mathrm{Max}}$, nearly $100 \%$ of identified biochemicals associated with cell death in a given pathway were elevated, suggesting an overall increase in biosynthesis to combat an overt exposure to redox stress (Figure 1).
Biochemicals in all enriched metabolic pathways relating to cell death were up-regulated at $\mathrm{T}_{\mathrm{c}, \mathrm{Max}}$, with progressively fewer biochemicals within each pathway elevated and/or reverting to down-regulation over time (Figure 1).

In a two-way ANOVA with contrasts evaluating changes across all time points, seven key biomarkers demarcated heat stress from control during recovery: 5,6-dihydrouracil, 3-ureidopropionate, GSSG, ornithine, creatinine, corticosterone and pyridoxal (Table 1).

\section{Redox stress and cell death}

The glutathione (GSH) metabolic network exhibited profound perturbation in response to heat stress (Figure 2). All three biochemicals involved in glutathione metabolism were elevated at $\mathrm{T}_{\mathrm{c}, \text { Max }}$, probably as a result of heatinitiated redox crisis (Figure 2). $\gamma$-Glutamylated amino acids (including alanine, glutamine, isoleucine, leucine, phenylalanine, tyrosine, and valine [Additional file 1]), 5-oxoproline, cysteine-GSH disulfide, and glutamate were significantly greater than control levels at $\mathrm{T}_{\mathrm{c}, \mathrm{Max}} \gamma^{-}$ Glutamylmethionine was slightly elevated at $\mathrm{T}_{\mathrm{c}, \mathrm{Max}}$, but the difference did not reach statistical significance

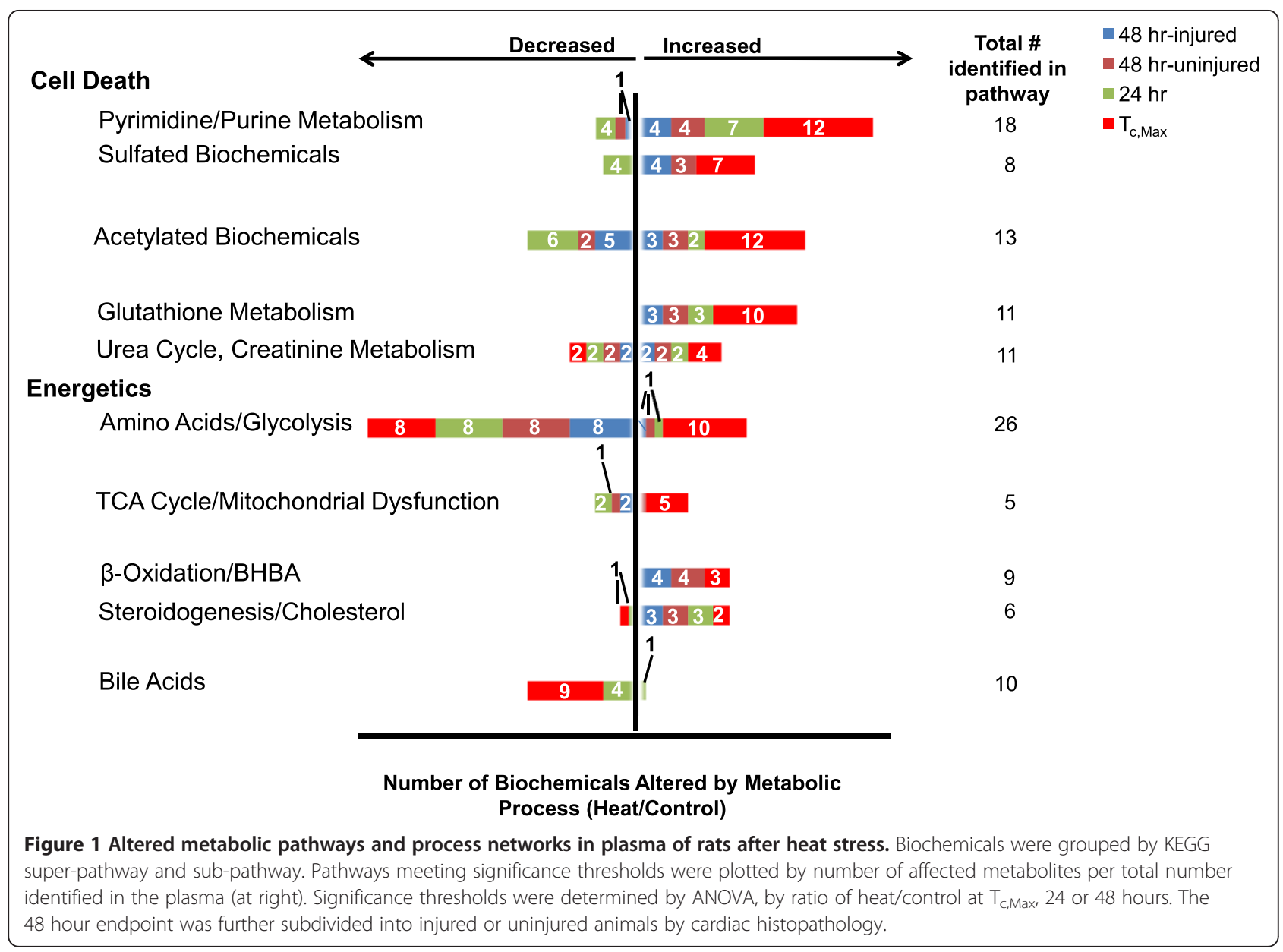


Table 1 List of seven key biochemical differentially expressed in heat-stressed and control animals*

\begin{tabular}{|c|c|c|}
\hline Identified biochemical (pathway) & Literature review (biochemical and/or pathway) & References \\
\hline $\begin{array}{l}\text { 5,6-Dihydrouracil (pyrimidine } \\
\text { metabolism) }\end{array}$ & Early signal of apoptosis; DNA damage from reactive oxygen species elevation; deficiency & {$[22-25]$} \\
\hline $\begin{array}{l}\text { 3-Ureidopropionate (alanine/ } \\
\text { aspartate metabolism) }\end{array}$ & $\begin{array}{l}\text { Increased reactive oxygen species; inhibition of mitochondrial energy metabolism; neurotoxic/ } \\
\text { excitotoxic }\end{array}$ & [26] \\
\hline $\begin{array}{l}\text { Ornithine (urea cycle, arginine } \\
\text { metabolism) }\end{array}$ & $\begin{array}{l}\text { Production of arginine and increase in autophagy, cell death, removal of excess } \mathrm{NH}^{+} \text {, energy } \\
\text { metabolism; slight renal dysfunction }\end{array}$ & [27] \\
\hline $\begin{array}{l}\text { Glutathione disulfide, oxidized } \\
\text { (redox) }\end{array}$ & $\begin{array}{l}\text { Apoptosis, DNA damage, cell proliferation, survival, differentiation, metabolism; redox stress and/ } \\
\text { or crisis due to elevated reactive oxygen species }\end{array}$ & {$[28-30]$} \\
\hline $\begin{array}{l}\text { Corticosterone (steroid/sterol } \\
\text { metabolism) }\end{array}$ & $\begin{array}{l}\text { Mitochondrial conversion of acetyl-CoA to cholesterol and conversion of cholesterol to } \\
\text { corticosterone; adrenal cortex production of cholesterol to pregnenalone, and ultimately } \\
\text { cortisol; involved in glucocorticoid activity and stress response }\end{array}$ & [31] \\
\hline $\begin{array}{l}\text { 7-a-Hydroxy-3-oxo-4-cholestenoate } \\
\text { [7-HOCA] (steroid/sterol metabolism) }\end{array}$ & Bile acid synthesis from cholesterol; CYP7A1 activity in the liver; bile acid synthesis & [32] \\
\hline Pyridoxal (vitamin B metabolism) & decreased renal function; Anabolism; cofactor for reaction releasing glucose from glycogen & [33] \\
\hline
\end{tabular}

*Not segregated based on cardiac injury.

(Additional file 1). At 24 and 48 hours, GSSG remained elevated. At 48 hours, three of the 11 biochemicals in GSH redox regulation remained elevated ( $\gamma$-glutamylphenylalanine, 5-oxoproline, and oxidized glutathione [GSSG]).

Production of reactive oxygen species (ROS) and oxidative stress occur when the cell's protective mechanisms are saturated. ROS also play key signaling roles in cell proliferation, survival, disease and pathophysiology [28]. Increased ROS may lead to apoptosis, DNA damage, cell proliferation, survival, differentiation, and disruption in metabolism [34]. Heat exposure elevates free radicals [29]. Free radicals and other ROS are neutralized by GSH in redox regulation cycles. Deficient and/or dysfunctional GSH can disrupt cell processes and lead to cell death [30]. Oxidized GSH can be reduced back by glutathione reductase with NADPH (nicotinamide adenine dinucleotide phosphate) as an electron donor. GSH donates a reducing equivalent to unstable redox species. Under normal physiological conditions, more than $90 \%$ of the glutathione pool is in the GSH form and less than $10 \%$ is in the disulfide GSSG form. The ratio of GSH to GSSG is a metric of cellular toxicity, with elevated GSSG

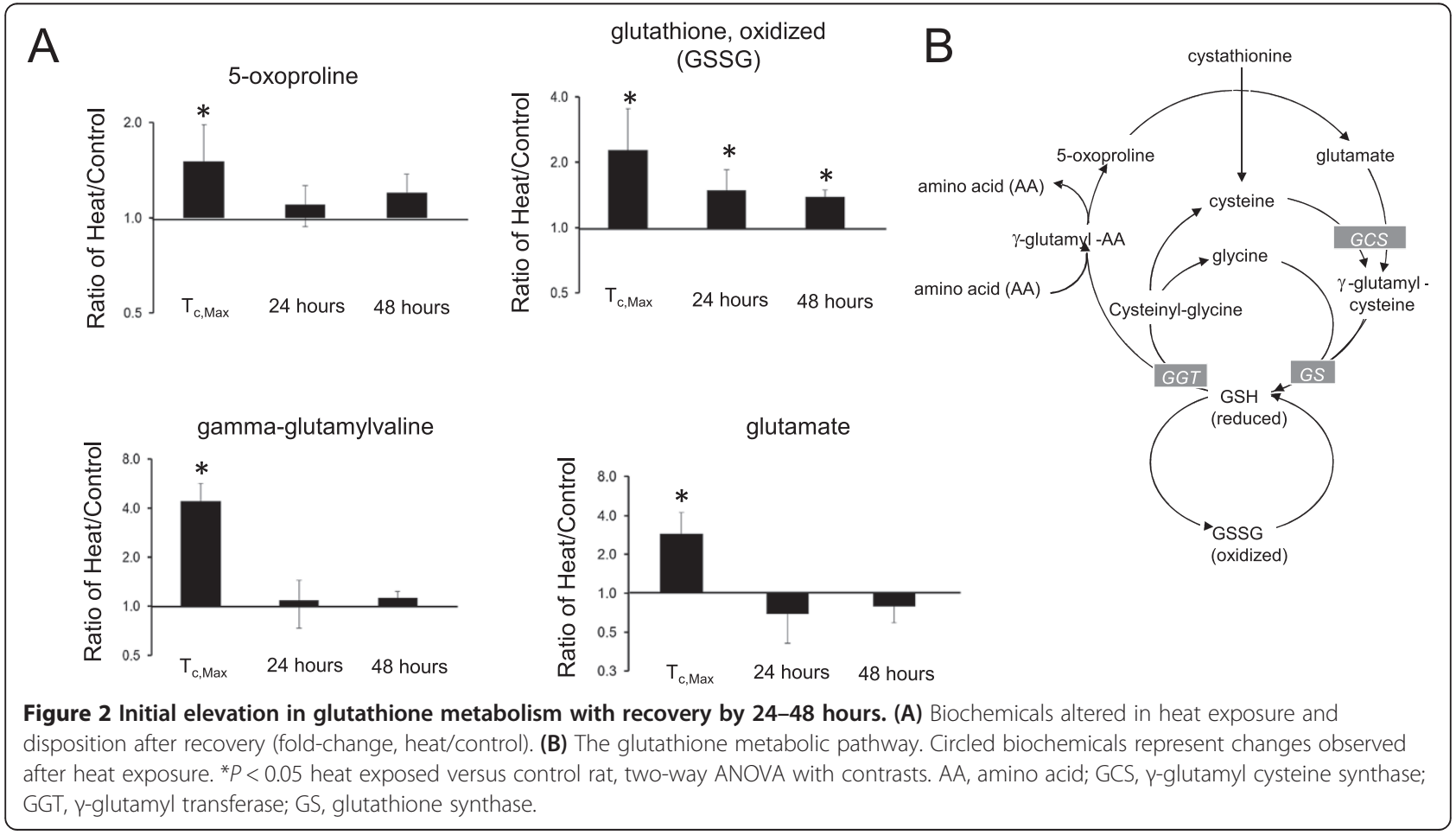


indicating oxidative stress [30]. Taken together, these results suggest that early perturbations in metabolic networks elicit persistent redox stress out to 48 hours after exposure. These persistent metabolic changes in heatstressed individuals may affect performance during subsequent episodes of heat injury.

\section{Arginine metabolism, nitric oxide metabolism, and cell death}

Six biochemicals involved in arginine metabolism were altered after heat exposure (Figure 3). These biochemicals were involved in the urea cycle, which feeds creatineto-creatinine production during metabolic mobilization of the muscle and/or brain energy reserves during energy crisis. Heat stress increased citrulline, decreased arginine, and increased urea in rat plasma at $\mathrm{T}_{\mathrm{c}, \mathrm{Max}}$ (Figure $3 \mathrm{~A}$ ). Trans-4-hydroxyproline was not significantly changed in concentration after heat stress (Additional file 1).

Elevated citrulline levels suggest a concomitant increase in nitric oxide, a product of inflammatory signaling (Figure 3B) [27]. Increased urea may be associated with cell death, autophagy, and/or protein degradation. The combination of elevated urea and creatinine could also suggest renal dysfunction, consistent with the proteinosis observed in the renal histopathology as reported in the companion study. Elevated plasma creatinine at later time points could indicate continued use of skeletal muscle energy reserves and persistent renal dysfunction. Concomitantly decreased arginine and increased urea may indicate slower kinetics of arginine metabolism with increased urea production (Figure 3B). Increased urea may also be the result of an increase in $\mathrm{NH}_{4}^{+}$, a byproduct of cellular death [35].

At 24 and 48 hours, citrulline levels were no longer elevated, suggesting that nitric oxide $(\mathrm{NO})$ production had decreased. Interestingly, however, ornithine levels increased at 24 and 48 hours, possibly reflecting slower arginine metabolism kinetics in general [36]. Taken together, these data suggest that a slight renal dysfunction was maintained during recovery, consistent with histopathologic evidence suggesting renal dysfunction.

\section{Purine/Pyrimidine metabolism and cell death}

Fourteen out of 18 identified biochemicals in the pyrimidine and purine metabolic pathways were significantly different at $\mathrm{T}_{\mathrm{c}, \mathrm{Max}}$ relative to control (Figure 1 and Additional file 2). Exceptions were adenosine monophosphate (AMP), uridine, cytosine, and dihydroorotate. Uracil, 5,6-dihydrouracil, 3-ureidopropionate, $\beta$-alanine, and an acetylated form of $\beta$-alanine, $N$-acetyl- $\beta$-alanine, were all significantly increased at $\mathrm{T}_{\mathrm{c}, \mathrm{Max}}$ compared to control rats, suggesting that a significant proportion of biochemicals involved in pyrimidine degradation was altered (Additional file 2). Significantly, nearly all the biochemicals immediately upstream of $\beta$-alanine metabolism in the pyrimidine metabolism reference Kyoto Encyclopedia of Genes and Genomes (KEGG) pathway are modulated, suggesting that a significant proportion of this biochemical network is affected by

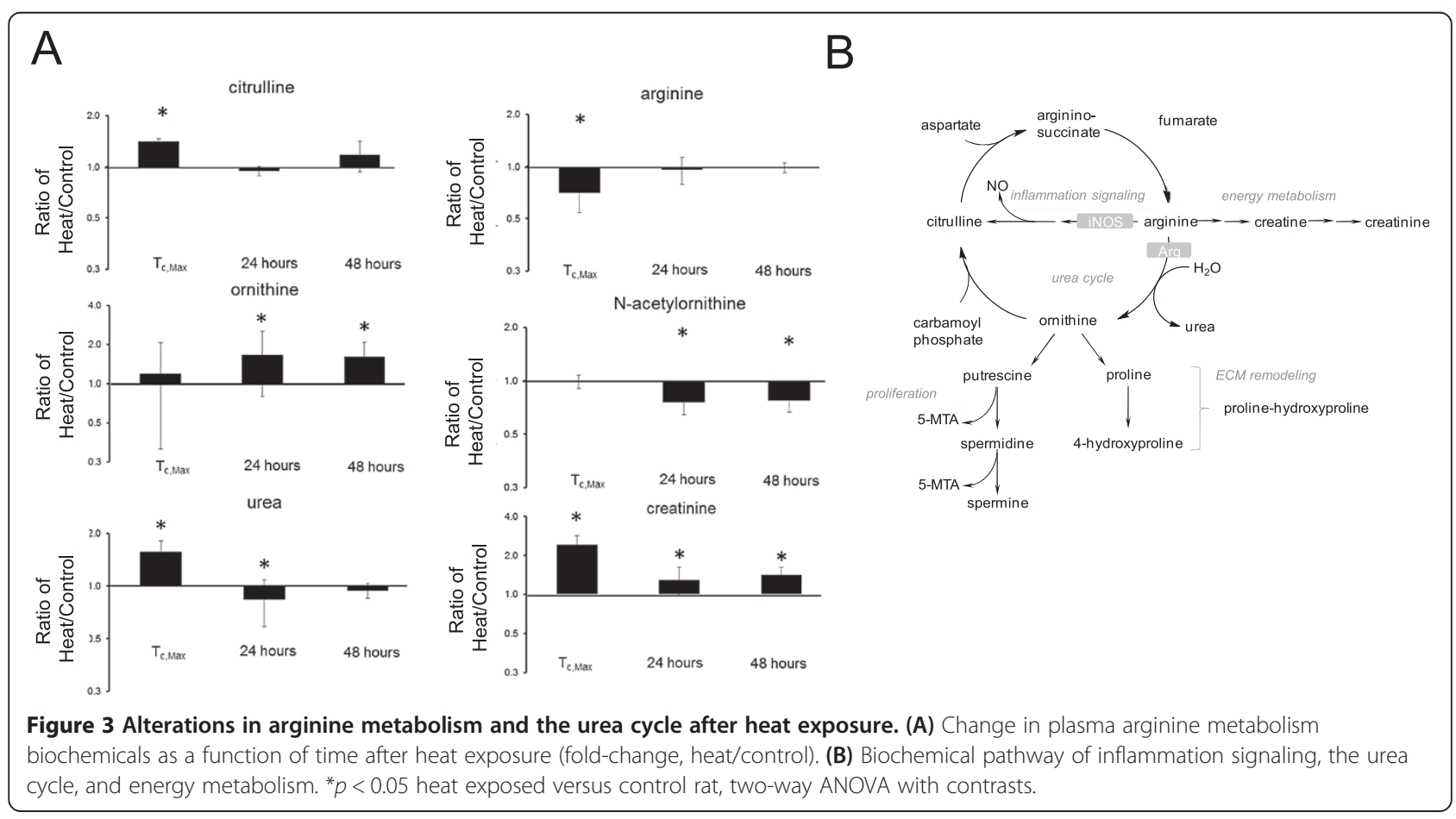


heat stress at $\mathrm{T}_{\mathrm{c}, \mathrm{Max}}$. In plant cells, alterations in pyrimidine nucleotide metabolism are considered an early signal of apoptosis and often are induced by an increase in endogenous NO [22]. 3-ureidopropionate, the substrate of the enzyme dihydropyrimidinase, was elevated (Additional file 1) while the product, 5,6-dihydrouracil, was decreased (Additional file 2), suggesting a down-regulation in the level of dihydropyriminidase activity or 3-ureidopropionate. Further, carnosine is synthesized from L-histidine and $\beta$ alanine, with $\beta$-alanine as the rate-limiting precursor [37], and 3 -ureidopropionate as the precursor to $\beta$-alanine production. The result of these alterations in pyrimidine degradation could suggest DNA damage by endogenous ROS over-riding cellular repair and protection mechanisms. Several altered biochemical pathways support elevated ROS.

\section{Acetylation or sulfation and cell death}

Of the N-acetylated biochemicals detected, 14 of 15 compounds were significantly elevated at $\mathrm{T}_{\mathrm{c}, \mathrm{Max}}$ (Additional file 3). While 8 of 15 biochemicals were significantly changed at 24 hours, 6 remained altered at 48 hours. Heat exposure appeared to change in the activity of acetyltransferases or deacetylases, consistent with cellular damage. This initial response probably reflects hypoxia and initiation of cell death [38]. Acetyltransferases and deacetylases may allow an organism to adapt to recovery.

Eight sulfated compounds were detected and at $\mathrm{T}_{\mathrm{c}, \mathrm{Max}}$, of which seven were significantly increased (Additional file 4). In addition, seven unnamed, putatively sulfated compounds also increased at $\mathrm{T}_{\mathrm{c}, \operatorname{Max}}(\mathrm{X}-12182, \mathrm{X}-12183, \mathrm{X}-12184$, $\mathrm{X}-12185, \mathrm{X}-12230$ and X-12307; Additional file 1). At 24 hours, all biochemicals which had been higher than control at $\mathrm{T}_{\mathrm{c}, \mathrm{Max}}$ were now significantly lower than controls, with a reversal of the trend after 48 hours (i.e., higher than controls; Additional file 4). Sulfotransferase enzymatic activity may have been induced or the activities of sulfatases may have reduced initially to facilitate clearance of cellular debris [35], then returned to control levels after recovery.

\section{Amino acids and cell death}

Of the 19 identified amino acids, seven were decreased and eight were increased relative to controls at $\mathrm{T}_{c, \mathrm{Max}}$, with a trend toward overall down-regulation at 24 hours and 48 hours. The exception was lysine, with a trend toward an increase at $\mathrm{T}_{\mathrm{c}, \mathrm{Max}}$, with elevations at both 24 and 48 hours (Additional file 5). At $\mathrm{T}_{\mathrm{c}, \mathrm{Max}}$, serine, threonine and alanine were lower than control. All three amino acids are synthesized from glycolytic intermediates. Although not definitive, these results may suggest a decrease in glycolysis [35]. Moreover, glutamate, which is consumed in the production of these amino acids, was increased at $\mathrm{T}_{\mathrm{c}, \mathrm{Max}}$. Whether these amino acid changes are indicative of energetic alterations or increased autophagy is unclear [39]. However, it is interesting to note that, at $\mathrm{T}_{\mathrm{c}, \mathrm{Max}}$, amino acids used as anaplerotic contributors to the TCA cycle (i.e., glutamate and the branched-chain amino acids leucine, isoleucine, and valine) were increased and amino acids potentially synthesized as a consequence of glycolysis were decreased (serine, alanine, and threonine) (Additional file 5). These results may indicate perturbations in glycolysis and an overall slowing of energy production.

\section{TCA cycle intermediates and energetics}

All five of the TCA cycle intermediates identified at $T_{c}$, Max were higher than controls (Figure 4), suggesting mitochondrial dysfunction and energy crisis. The concomitant increase in 2-hydroxybutyrate (AHB) further supported a perturbation in mitochondrial function [35]. By 24-48 hours, TCA metabolites in the plasma were no longer significantly elevated, suggesting restoration of the TCA cycle to homeostasis.

\section{$\beta$-Oxidation, cholesterol synthesis, and bile acids}

3-Hydroxybutyrate (BHBA) and carnitines were significantly increased at $\mathrm{T}_{\mathrm{c}, \mathrm{Max}}$ (Additional file 6), supporting an increase in fatty acid $\beta$-oxidation for energy production. Increased $\beta$-oxidation is also implied from a trend toward lower plasma levels of the medium-chain fatty acids (e.g., palmitoylcarnitine, stearoylcarnitine, and oleoylcarnitine) relative to controls. These fatty acids can enter the mitochondria without requiring transporter activity (Additional file 6). Further, hexanoylcarnitine, a long-chain fatty acid conjugated to carnitine to facilitate entry into the mitochondria [35], is increased in heated animals. Increased $\beta$-oxidation may increase levels of acetyl coenzyme A (acetyl CoA) (Additional file 1, Additional file 6A), but the profound down-regulation in glycolysis, TCA cycle, and amino acid metabolism suggests that the acetyl CoA is not being used for adenosine triphosphate (ATP) production at $\mathrm{T}_{\mathrm{c}, \mathrm{Max}}$.

$\beta$-Oxidation may also be up-regulated to facilitate cholesterol synthesis and corticosterone production [35]. At $\mathrm{T}_{\mathrm{c}, \mathrm{Max}}$, corticosterone was significantly increased in heated animals relative to controls, and the increase persisted to 24-48 hours (Additional file 6). The increase in BHBA may reflect an increase in acetyl CoA for subsequent cholesterol metabolism and steroidogenesis, but functional mitochondria are required for this process. Alternatively, the elevated corticosterone could be released from the adrenal cortex during heat stress as part of a generalized stress response. Studies suggest prophylactic treatment with glucocorticoids protects against heat stress [40]. Changes in corticosterone levels could gauge severity of perturbations during heat and recovery [31].

Bile acids and steroids are generated from cholesterol. Following heat stress, plasma levels of steroids increased 


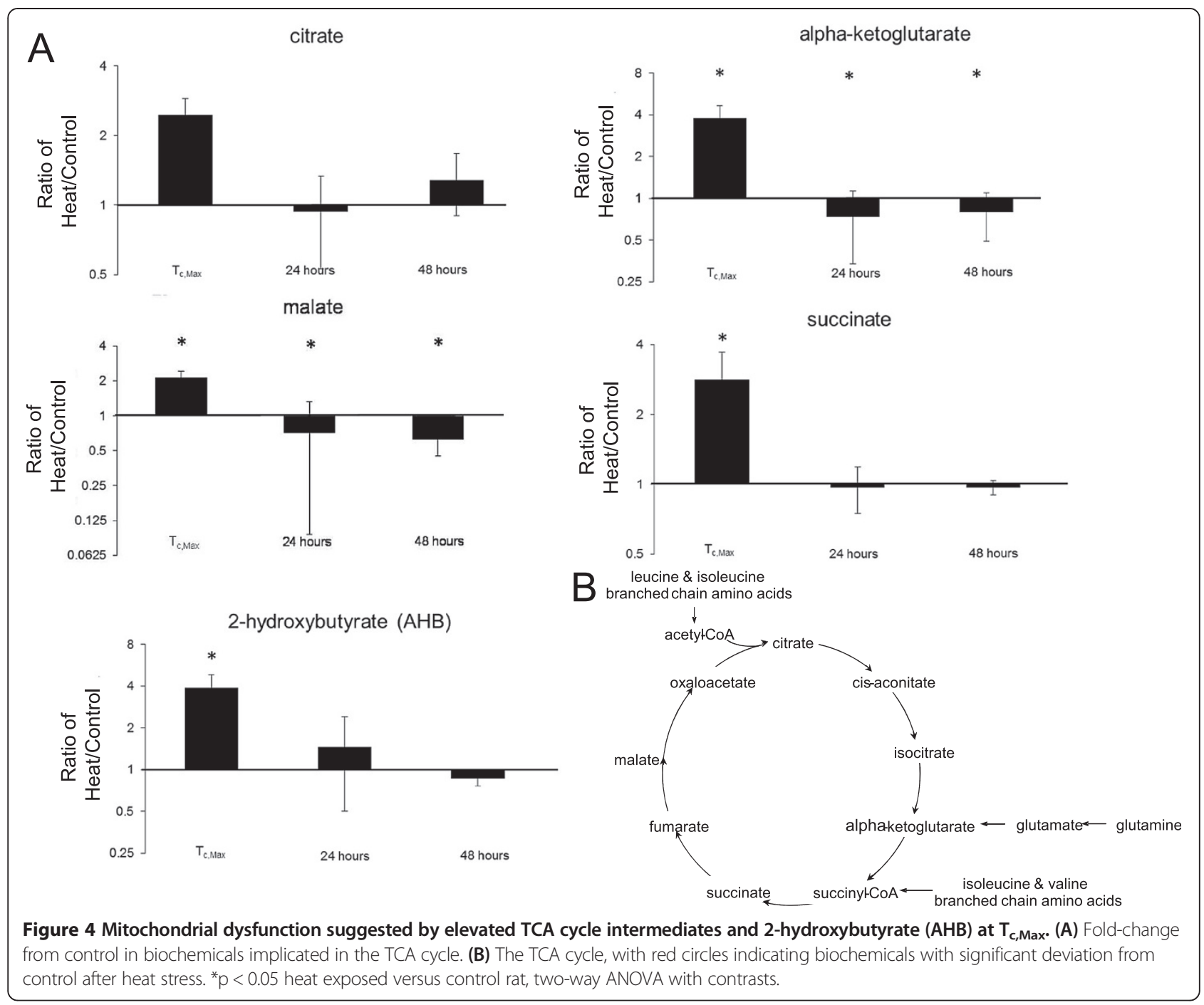

with a concomitant decrease in bile acids, suggesting de novo steroidogenesis (Additional file 7). Bile acid concentration is usually low in the normal systemic circulation. With heat stress, levels of nearly all bile acids detected were even lower at $\mathrm{T}_{c, \operatorname{Max}}$ (Additional file 7 ), possibly due to decreased reuptake within the small intestine and constricted intestinal circulation [41].

\section{Co-factor metabolism}

In addition to the broad categories of energetics and cell death, metabolites of Vitamin $\mathrm{B}_{6}$ are altered by heat stress (Additional file 8). Heat stress resulted in an accumulation of pyridoxate (a breakdown product secreted in the urine), potentially reflecting renal dysfunction. Pyridoxal levels were increased in heated animals relative to controls at $\mathrm{T}_{\mathrm{c}, \mathrm{Max}}$, possibly due to increased catabolism. In contrast, pyridoxal and pyridoxate levels were lower than control at 24-48 hours, possibly due to increased anabolism (a process that requires $B_{6}$ as a cofactor) and return to homeostasis (Additional file 8).

\section{Data integration-random forest analysis to identify biochemicals which discriminate heat exposure from unheated controls}

Taken together, the results of the metabolic pathway analysis supports a model of heat stress perturbing metabolic networks affecting cell death and energetics. Ultimately, these metabolic network perturbations lead to disruption of cholesterol and bile acid synthesis, nitric oxide production and inflammatory signaling, and vitamin $\mathrm{B}_{6}$ cofactor regulation (Figure 5). Performing integrated ANOVA analysis across biochemicals at all time points identified seven biomarkers within five metabolic networks which discriminated heat stressed individuals from controls at any time point (Figure 5). 


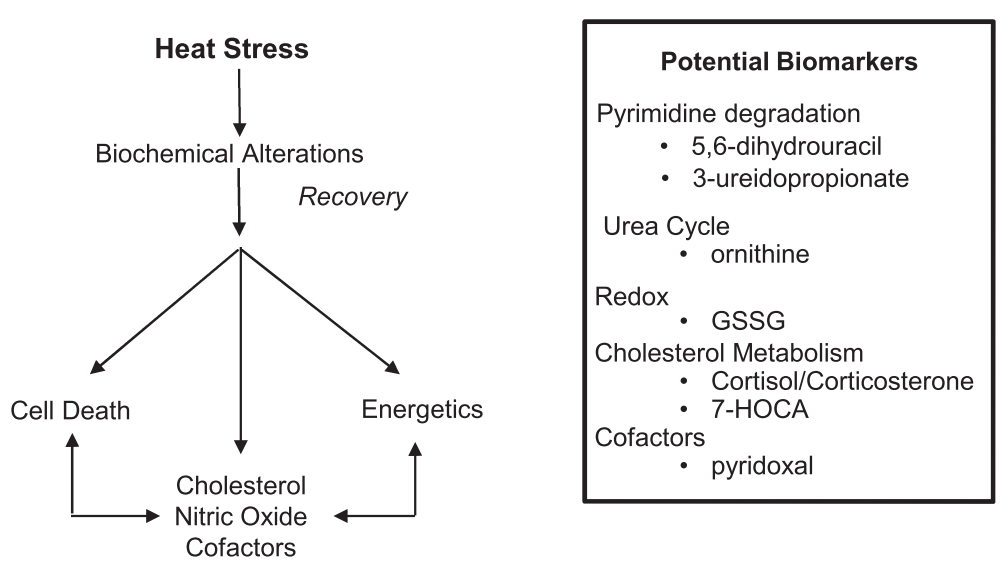

Figure 5 Model of heat stress and recovery and potential biomarkers. Hierarchical clustering was used to compare heated and control animals 48 hours after heat exposure. Data clustered by cardioinflammation score in animals with the greatest histopathological evidence of injury.

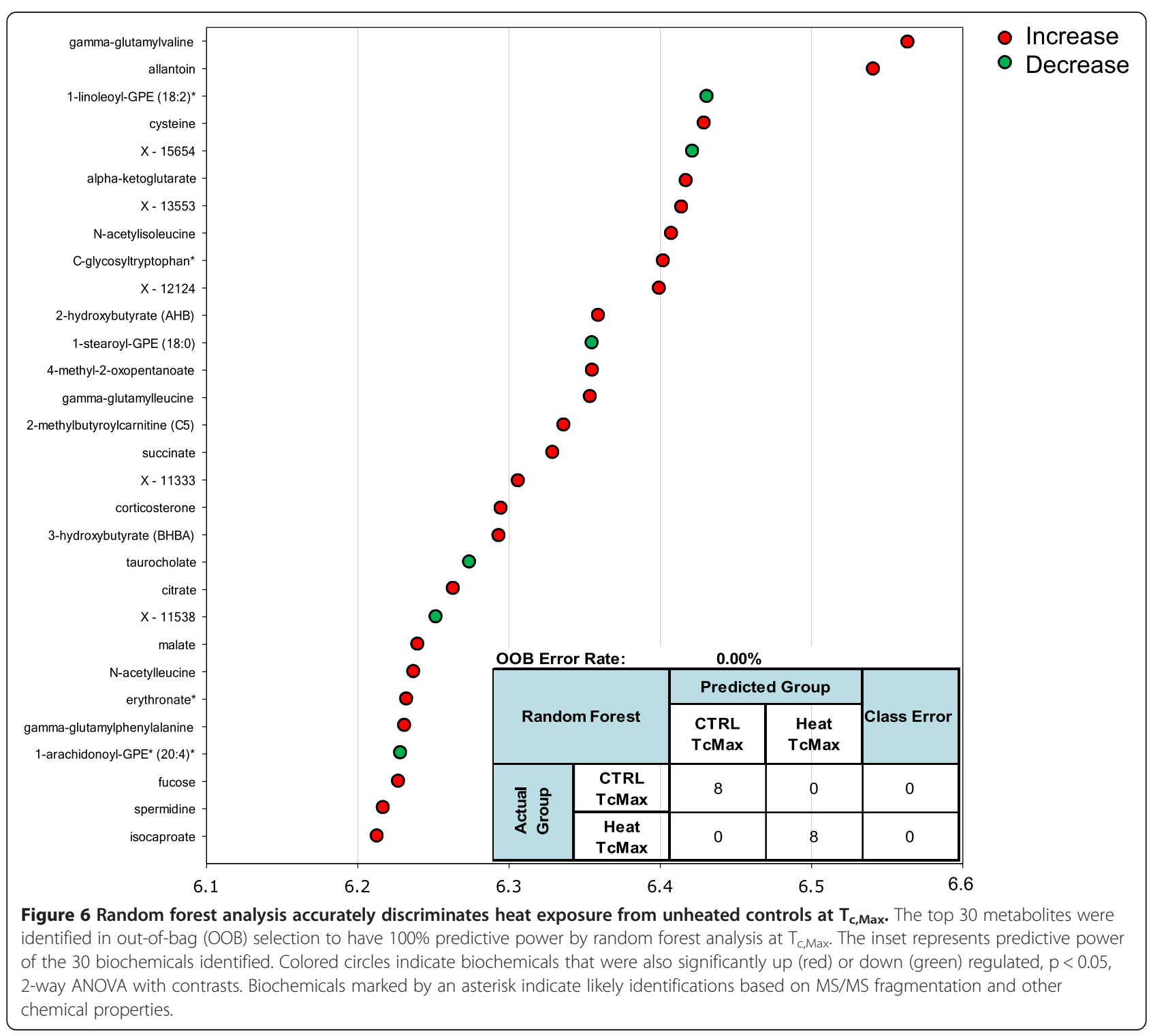


Random forest statistical analyses were used to determine sets of biomarkers capable of discriminating control from heat stress at $\mathrm{T}_{\mathrm{c}, \mathrm{Max}}$ (Figure 6), 24 hours (Figure 7) and 48 hours (Figure 8 ) after exposure to heat. The out-of-bag (OOB) error rate for each forest plot was $0 \%$, $6.25 \%$, and $0 \%$, respectively. The top predictive chemicals at $\mathrm{T}_{\mathrm{c}, \mathrm{Max}}$ were $\gamma$-glutamylvaline and allantoin (Figure 6). Allantoin is not typically found in humans, but $\gamma$ glutamylvaline is elevated in response to perturbations in the redox cycle [28] (see also Figure 2). At 24 hours, the top predictive chemicals were C-glycosyltryptophan, $\mathrm{N}$ acetyl- $\beta$-alanine, and asparagine (Figure 7 ). The predictive power of the model was slightly lower than $\mathrm{T}_{\mathrm{c}, \mathrm{Max}}$, but still predicted with nearly $94 \%$ accuracy. At 48 hours, the most predictive biochemicals were 5-methyl-2'deoxycytidine, pyridoxate, 3-methylhistidine, palmitoylcarnitine (C16), erythritol, 3-(4-hydroxphenyl) lactate (HPLA), pseudouridine, oleoylcarnitine (C18), and X-12408 (Figure 8).
The degradation product of DNA (5-methyl-2'-deoxycytidine) and pseudouridine (a representative of RNA degradation) are both likely representative of continued cell death (see also Additional file 2) [22].

\section{Identification of predictive indicators of persistent cardiac} injury at $\mathbf{4 8}$ hours

At 48 hours, three out of six heated animals showed histopathological evidence of cardiac injury (see companion study). Segregating injured from uninjured animals did not result in significant differences at 48 hours for any biochemical pathway grouping except acetylation and sulfation (Additional files 1, 3, and 4). Using hierarchical clustering at 48 hours, we evaluated the global change in metabolites after heat exposure, segregating the 48 hour animals into injured and uninjured cohorts ( $\mathrm{n}=3$ per cohort). A panel of 15 biochemicals discriminated animals with histopathologic evidence of heart

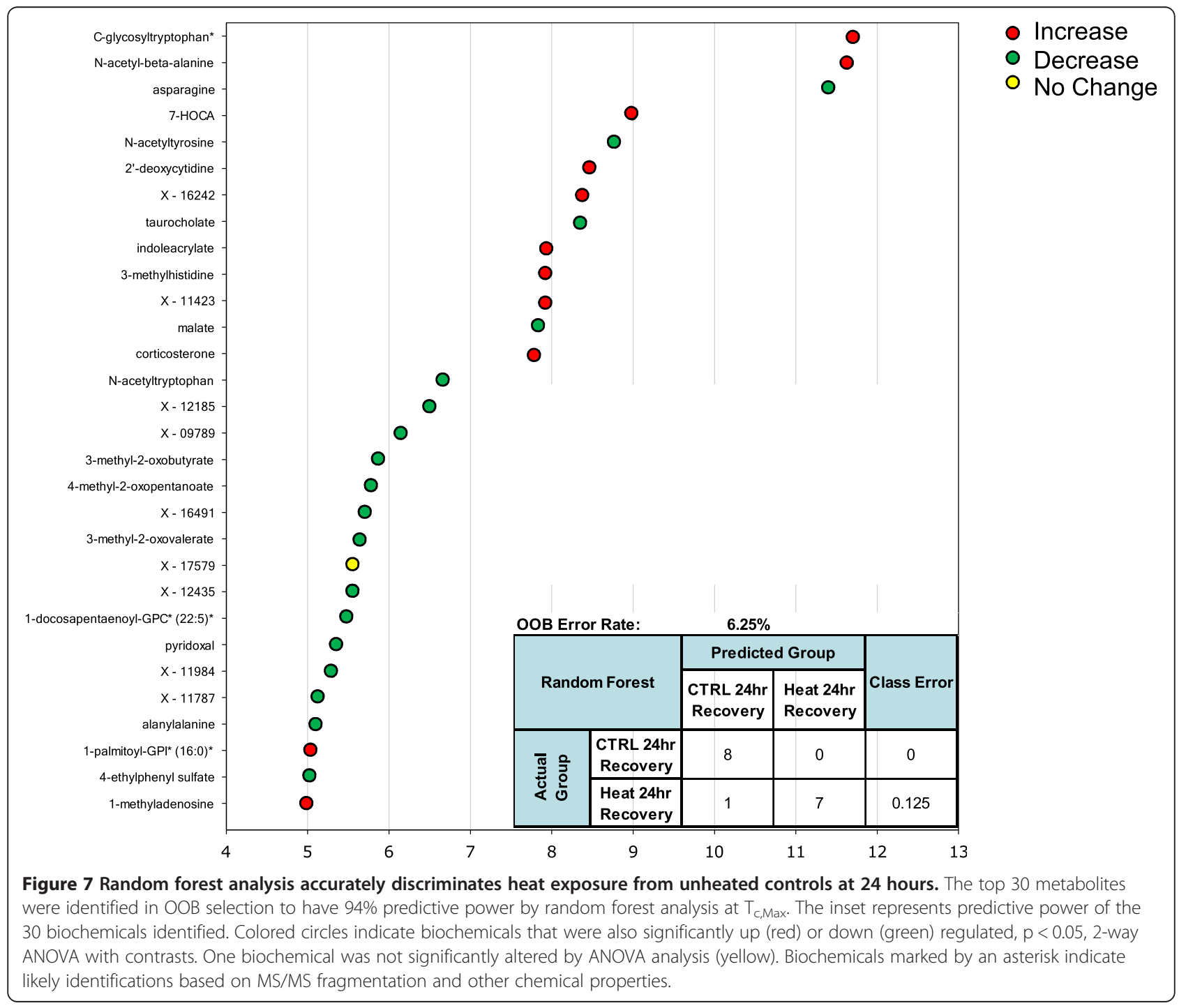




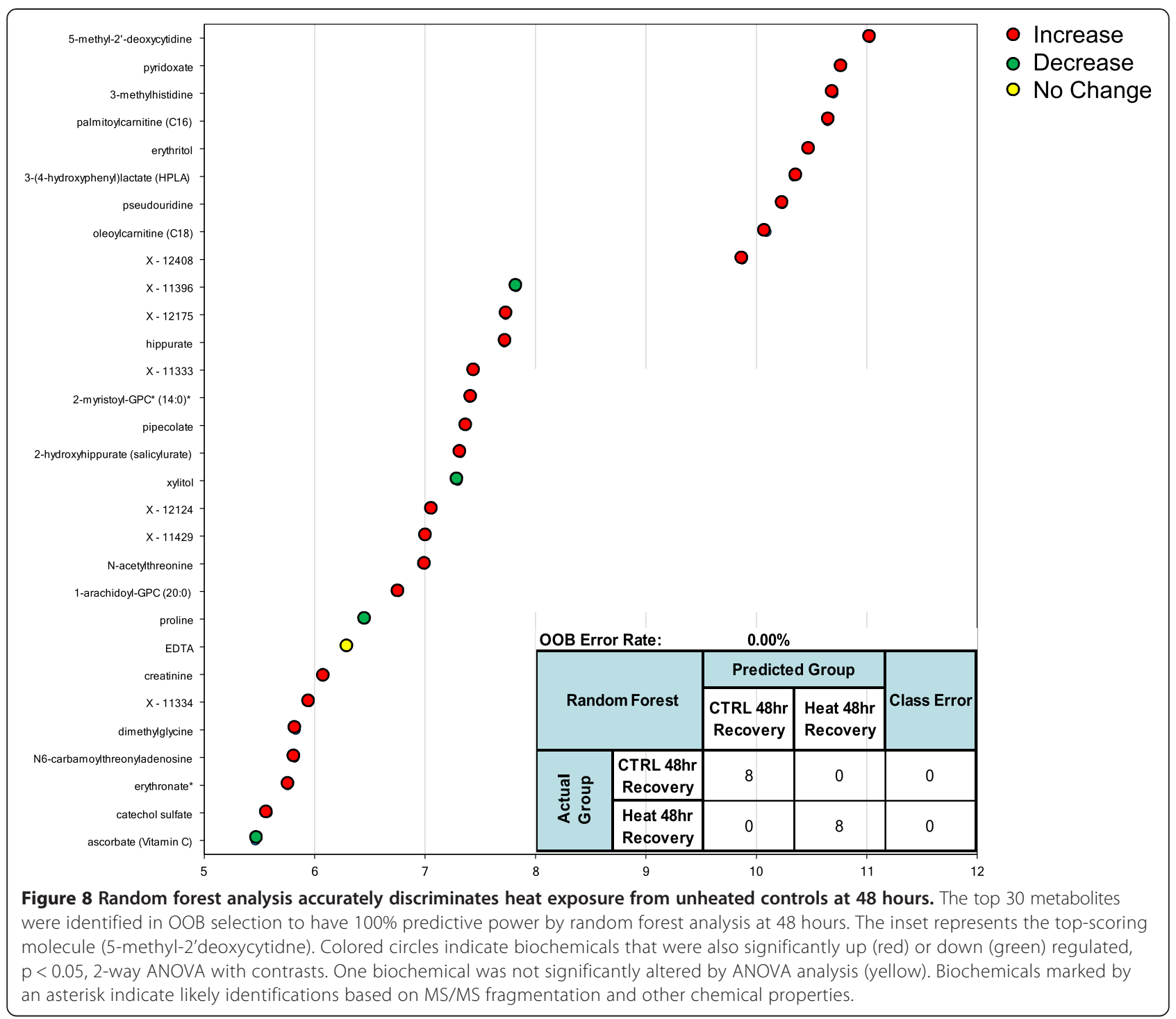

injury from controls and uninjured, heated animals (Figure 9). Biochemicals in the panel were sub-categorized by metabolic pathway (Table 2). Ornithine and N1methyladenosine and taurodeoxycholate have been associated with cardiac injury (summarized in Table 2).

The results of the random forest analyses at each time point were most concordant with the two-way ANOVA analysis at 24 hours (two of the seven biomarkers identified in both analyses-7-HOCA and corticosterone). At $\mathrm{T}_{\mathrm{c}, \mathrm{Max}}$, only corticosterone was common to both analyses, and at 48 hours, only pyroxidate was common to both analyses. It is important to note, however, that 88 of the 90 biochemicals that were excellent classifiers of exposure were also significantly altered according to the ANOVA analyses (as indicated by the red and green circles in Figures 6, 7, 8). Thus, rather than the manual and somewhat arbitrary selection of the top seven biochemical based on circulating levels, the random forest analysis pulls out a list of chemicals that in combination (whether up- or down-regulated) provide greater discriminatory power than a single biomarker, which may be a more powerful approach in populations that demonstrate significant individual variability in the metabolic response across time points.

\section{Comparison of metabolic networks enriched in heat injury with complementary proteomics and transcriptomics pathway analysis}

The strength of metabolomics is in its analysis of hundreds of analytes simultaneously. Multiple small changes $(<2$-fold) within a given biochemical pathway can signal a physiologically relevant perturbation of a physiological network regulating a metabolic function [58]. These physiologically relevant changes may be overlooked in 


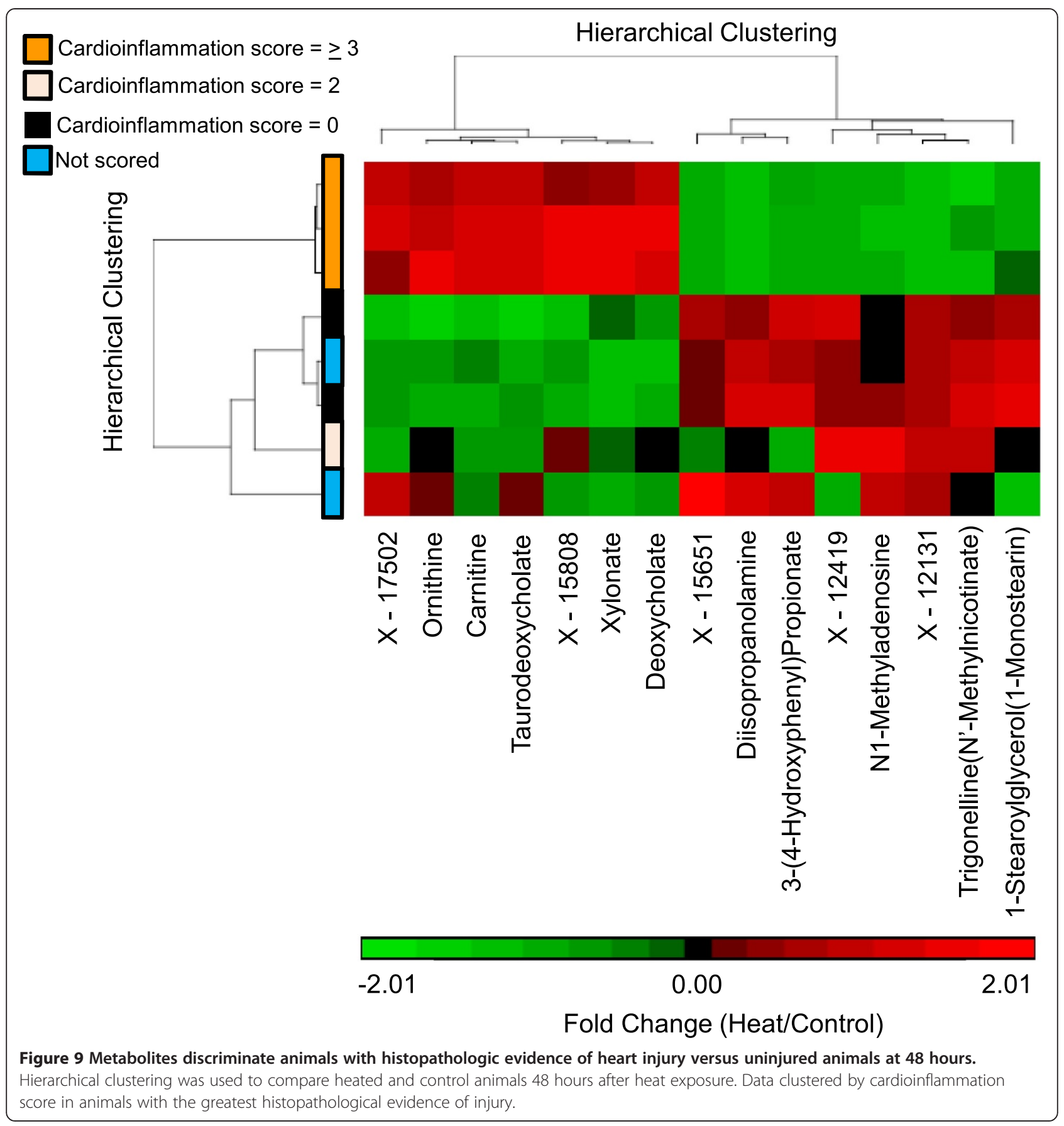

the analysis of single analytes. The network-wide comparison of plasma metabolites complements the transcriptomic and proteomic profiles observed in cardiac tissue in our recently published study [19]. The greatest concordance was observed in down-regulated biomolecules among KEGG pathways enriched in the three data sets (Figure 10). Metabolomics, proteomics, and transcriptomics data integration suggests concurrence in the transcripts, proteins, and metabolites supporting a downregulation of oxidative phosphorylation and the TCA cycle. Taken together, these results support energy crisis and oxidative stress at 48 hours in cardiac-injured animals. Importantly, the metabolomics data obtained in plasma are concordant with tissue-based proteomics and transcriptomics profiles at the pathway level. Sampling blood (an accessible biofluid) indicates cardiac distress at the tissue level in this study. The metabolomics data were more discordant than the proteomics and the transcriptomics data, especially when comparing up-regulated genes and proteins with metabolites in the corresponding KEGG 
Table 2 Review of 15 metabolites differentiating animals with histopathological evidence of cardioinflammation from uninjured animals

\begin{tabular}{|c|c|c|}
\hline Identified biochemical (pathway) & Literature review (biochemical and/or pathway) & References \\
\hline $\begin{array}{l}\text { Ornithine (phenylalanine and tyrosine } \\
\text { metabolism) }\end{array}$ & $\begin{array}{l}\text { inhibition of nitric oxide; relationship between nitric oxide modulation of the Frank- } \\
\text { Starling response in heart; nitric oxide and nitric oxide synthase are sensitive to thermal } \\
\text { stress in fish }\end{array}$ & [42] \\
\hline $\begin{array}{l}\text { 3-(4-Hydroxyphenyl) propionate } \\
\text { (phenylalanine and tyrosine metabolism) }\end{array}$ & $\begin{array}{l}\text { Biological nitrification inhibition (in plants); phenylalanine and tyrosine concentrations } \\
\text { are reduced after Hsp70 increase and heat stress (in yeast) }\end{array}$ & {$[43,44]$} \\
\hline $\begin{array}{l}\text { N1-Methyladenosine (purine metabolism, } \\
\text { adenine containing) }\end{array}$ & $\begin{array}{l}\text { N1-methyladenosine analogues are cardioprotective agents in ischemic reperfusion } \\
\text { model; decreased infarction; purine metabolism associated with myocardial steatosis and } \\
\text { down-regulation of adipose triglyceride In heart }\end{array}$ & {$[45,46]$} \\
\hline $\begin{array}{l}\text { Xylonate (nucleotide sugars, pentose } \\
\text { metabolism) }\end{array}$ & $\begin{array}{l}\text { Deficiency in pentose metabolism produces a protective effect through decreased } \\
\text { cholesterol synthesis, superoxide production, and reductive stress }\end{array}$ & [47] \\
\hline $\begin{array}{l}\text { 1-Stearoylglycerol (1-Monostearin) } \\
\text { (monoacylglycerol) }\end{array}$ & $\begin{array}{l}\text { Associated with increased lipid catabolism and remodeling mitochondrial oxidation to } \\
\text { aerobic glycolysis (hepatocellular carcinoma) }\end{array}$ & [48] \\
\hline Carnitine (carnitine metabolism) & $\begin{array}{l}\text { Disrupted carnitine metabolism is associated with mitochondrial dysfunction and } \\
\text { increased pulmonary flow (lamb model); cardioprotective by increasing heat shock } \\
\text { protein synthesis in adriamycin-induced cardiomyopathy }\end{array}$ & [49-51] \\
\hline Taurodeoxycholate (bile acid metabolism) & $\begin{array}{l}\text { Bile acids exert a protective effect after ischemic injury in porcine hearts; cause } \\
\text { endoplasmic reticulum mitochondrial stress; deoxycholate and taurodeoxycholate affect } \\
\text { heart mitochondria by decreasing respiration, affecting membrane potential, inducing } \\
\text { mitochondrial permeability transition, and altering mitochondrial bioenergetics; impaired } \\
\text { cardiac mitochondrial function may cause cardiac alterations in cholestasis }\end{array}$ & {$[52-55]$} \\
\hline Deoxycholate (bile acid metabolism) & (see above) & (see above) \\
\hline $\begin{array}{l}\text { Trigonelline ( } \mathrm{N}^{\prime} \text {-Methylnicotinate) (nicotinate } \\
\text { and nicotinamide metabolism) }\end{array}$ & $\begin{array}{l}\text { Cardioprotective effects after isoproterenol induced myocardial dysfunction (reduction in } \\
\text { Hsp27, aB-crystallin and calcium/calmodulin dependent kinase-II- } \delta \text { ) }\end{array}$ & [56] \\
\hline $\begin{array}{l}\text { Diisopropanolamine (xenobiotics - chemical } \\
\text { metabolism) }\end{array}$ & $\begin{array}{l}\text { Increases choline uptake without affecting phospholipid synthesis (Chinese hamster } \\
\text { ovary cells) }\end{array}$ & [57] \\
\hline$X-17502$ (Unknown) & $\mathrm{n} / \mathrm{a}$ & $\mathrm{n} / \mathrm{a}$ \\
\hline$X-12419$ (unknown) & $\mathrm{n} / \mathrm{a}$ & $\mathrm{n} / \mathrm{a}$ \\
\hline X - 15808 (unknown) & $\mathrm{n} / \mathrm{a}$ & $\mathrm{n} / \mathrm{a}$ \\
\hline X - 12131 (unknown) & n/a & $\mathrm{n} / \mathrm{a}$ \\
\hline$X-15651$ (unknown) & $\mathrm{n} / \mathrm{a}$ & $\mathrm{n} / \mathrm{a}$ \\
\hline
\end{tabular}

pathways. However, amino acid/nucleotide sugar metabolism were modulated at the transcript, protein, and metabolite level, supporting a stasis of energy production/energy crisis (Figure 11). Combined with the panel of potential cardiac injury markers (Figure 9), these results suggest a plasma-based series of metabolic indicators for tissue damage induced by heat stress. Detecting biomarkers predictive of cardiac injury in an accessible biofluid supports further studies investigating whether these metabolites represent viable biomarker candidates for predicting cardiac injury and recovery.

\section{Conclusion}

In this work, we present a plasma metabolomic profile of heat stress and heat injury in an in vivo rodent model of heat stress. The metabolomic profile in plasma is concordant with tissue proteomics and transcriptomic profiles indicating energy crisis and oxidative stress, suggesting that metabolic indicators in the plasma may provide surrogate markers for tissue injury in an accessible biofluid. Coupled with the earlier work in tissue transcriptomics and proteomics in the heat-stressed rodent model [19], the global metabolomic profiles identified the basis for future work for modeling the response to heat stress and heat injury [18]. Integration of metabolomics, proteomics, and transcriptomics in a top-down manner will provide the foundation for network analysis and computational based experiments in a human 3D thermoregulation model [59]. Anchoring these systemic stress responses to the physiological model of heat stroke will provide further insight into forecasting risk of disease, timing of disease onset, and intensity of disease at the organ level. As a result, we anticipate that such a model would accelerate the development of tools to improve disease prevention, classification, and ultimately treatment.

\section{Methods}

\section{Materials and methods}

Animal model

In vivo rat experiments were performed at the US Army Research Institute of Environmental Medicine (USARIEM). The Institutional Animal Care and Use Committee 


\begin{tabular}{|c|c|c|c|c|c|c|c|c|c|}
\hline \multicolumn{3}{|l|}{$\begin{array}{l}\text { Transcriptomics }^{*} \\
\end{array}$} & \multicolumn{3}{|c|}{ Proteomics (iTRAQ) ${ }^{*}$} & \multicolumn{4}{|c|}{ Metabolomics* } \\
\hline $\begin{array}{l}\text { Pathways enriched in animals with } \\
\text { cardiac injury }\end{array}$ & Count & P-value & $\begin{array}{l}\text { Pathways enriched in animals } \\
\text { with cardiac injury }\end{array}$ & Count & P-value & $\begin{array}{l}\text { Pathways enriched in } \\
\text { animals with cardiac injury }\end{array}$ & $\begin{array}{c}\text { Complementary KEGG } \\
\text { designation (DAVD) }\end{array}$ & \multicolumn{2}{|c|}{ \# identified \# changed } \\
\hline rno00190:Oxidative phosphorylation & 63 & $2.1 E-37$ & rno05012:Parkinson's disease & 46 & 4.6E-44 & Oxidative phosphorylation & $\begin{array}{c}\text { rno00190: Oxidative } \\
\text { phosphorylation }\end{array}$ & 2 & 1 \\
\hline mo05012:Parkinson's disease & 61 & $4.3 \mathrm{E}-34$ & $\begin{array}{l}\text { mo00190: Oxidative } \\
\text { phosphorylation }\end{array}$ & 44 & $9.0 E-42$ & & & & \\
\hline $\begin{array}{l}\text { rno05016: Huntington's disease } \\
\text { mo05010:Azheimer's disease }\end{array}$ & $\begin{array}{l}63 \\
62\end{array}$ & $\begin{array}{l}1.1 E-27 \\
7.6 E-26\end{array}$ & $\begin{array}{l}\text { mo05016: Huntington's disease } \\
\text { mo05010:Azheimer's disease }\end{array}$ & $\begin{array}{l}47 \\
45\end{array}$ & $\begin{array}{l}4.4 E-39 \\
1.3 E-35\end{array}$ & & & & \\
\hline mo04260:Cardiac muscle contraction & 33 & $4.9 \mathrm{E}-18$ & mo00020:Citrate cycle (TCA & 17 & $4.0 E-20$ & Citrate cycle (TCA cycle) & mo00020:Citrate cycle (TCA cycle) & 4 & 4 \\
\hline $\begin{array}{l}\text { mo00280:Valine, leucine and isoleucine } \\
\text { degradation }\end{array}$ & 23 & $2.0 \mathrm{E}-14$ & $\begin{array}{l}\text { mo04260: Cardiac muscle } \\
\text { contraction }\end{array}$ & 23 & $5.2 E-20$ & Ketone bodies & $\begin{array}{l}\text { rno00072: Synthesis and } \\
\text { degradation of ketone bodies }\end{array}$ & 2 & 2 \\
\hline mo00020:Citrate cycle (TCA cycle) & 18 & $5.3 \mathrm{E}-13$ & $\begin{array}{l}\text { rno00280:Valine, leucine and } \\
\text { isoleucine degradation }\end{array}$ & 13 & $7.0 \mathrm{E}-11$ & Fatty acid, dicarboxylate & $\begin{array}{l}\text { mo00630:Glyoxylate and } \\
\text { dicarboxylate metabolism }\end{array}$ & 2 & 7 \\
\hline rno05414:Dilated cardiomyopathy & 28 & $1.6 \mathrm{E}-11$ & mo00071:Fatty acid metabolism & 11 & $7.8 \mathrm{E}-09$ & $\begin{array}{l}\text { Nicatinate and nicotinamide } \\
\text { metabolism }\end{array}$ & $\begin{array}{l}\text { mo000760: Nicotinate and } \\
\text { nicotinamide metabolism }\end{array}$ & 2 & 1 \\
\hline $\begin{array}{l}\text { mo05410:Hypertrophic cardiomyopathy } \\
\text { (HCM) }\end{array}$ & 26 & $1.1 \mathrm{E}-10$ & mo00640:Propanoate metabolism & 10 & 1.2E-08 & & & & \\
\hline rno00071:Fatty acid metabolism & 17 & $4.9 \mathrm{E}-09$ & mo00650:Butanoate metabolism & 9 & $2.3 \mathrm{E}-07$ & & & & \\
\hline rno00640:Propanoate metabolism & 14 & $8.9 E-08$ & $\begin{array}{l}\text { rno00062:Fatty acid elongation in } \\
\text { mitochondria }\end{array}$ & 5 & 1.1E-05 & & & & \\
\hline $\begin{array}{l}\text { mo05412:Arrhythmogenic right } \\
\text { ventricular cardiomyopathy (ARVC) }\end{array}$ & 19 & $1.4 \mathrm{E}-06$ & $\begin{array}{l}\text { rno05410: Hypertrophic } \\
\text { cardiomyopathy (HCM) }\end{array}$ & 9 & $3.0 E-04$ & & & & \\
\hline mo00650:Butanoate metabolism & 12 & $6.1 \mathrm{E}-06$ & rno05414:Dilated cardiomyopathy & 9 & $4.8 \mathrm{E}-04$ & & & & \\
\hline $\begin{array}{l}\text { rno03320:PPAR signaling pathway } \\
\text { rno00620:Pyruvate metabolism }\end{array}$ & $\begin{array}{l}17 \\
12\end{array}$ & $\begin{array}{l}1.5 \mathrm{E}-05 \\
3.7 \mathrm{E}-05\end{array}$ & & & & & & & \\
\hline $\begin{array}{l}\text { mo00760: Nicotinate and nicotinamide } \\
\text { metabolism }\end{array}$ & 8 & $6.0 \mathrm{E}-04$ & & & & & & & \\
\hline rno00230:Purine metabolism & 20 & $7.8 \mathrm{E}-03$ & & & & & & & \\
\hline $\begin{array}{l}\text { mo00062:Fatty acid elongation in } \\
\text { mitochondria }\end{array}$ & 4 & $1.3 \mathrm{E}-02$ & & & & & & & \\
\hline $\begin{array}{l}\text { mo04920:Adipocytokine signaling } \\
\text { pathway }\end{array}$ & 11 & $1.4 \mathrm{E}-02$ & & & & & & & \\
\hline $\begin{array}{l}\text { rno00072: Synthesis and degradation of } \\
\text { ketone bodies }\end{array}$ & 4 & $1.9 \mathrm{E}-02$ & & & & & & & \\
\hline $\begin{array}{l}\text { mo00360:Phenylalanine metabolism } \\
\text { mo00380:Tryptophan metabolism }\end{array}$ & $\begin{array}{l}5 \\
8\end{array}$ & $\begin{array}{l}2.0 \mathrm{E}-02 \\
2.4 \mathrm{E}-02\end{array}$ & & & & & & & \\
\hline $\begin{array}{l}\text { mo00630: Glyoxylate and dicarboxylate } \\
\text { metabolism }\end{array}$ & 4 & $4.3 \mathrm{E}-02$ & & & & & & & \\
\hline $\begin{array}{l}\text { Figure } 10 \text { Down-regulated } \\
\text { compared across transcriptor } \\
\text { designation is listed along wi } \\
\text { proteomics and transcriptom } \\
\text { two data sets, with the same } \\
\text { (up-regulated or down-regula }\end{array}$ & $\begin{array}{l}\text { biom } \\
\text { mics, } \\
\text { ith the } \\
\text { ics res } \\
\text { directi } \\
\text { ted) } d\end{array}$ & $\begin{array}{l}\text { larkers } \\
\text { broteon } \\
\text { comp } \\
\text { colts we } \\
\text { on in a } \\
\text { iffers. }\end{array}$ & $\begin{array}{l}\text { edictive of cardiac inju } \\
\text { and metabolomics stu } \\
\text { lentary KEGG designatio } \\
\text { described in detail in a } \\
\text { ta sets (up-regulated or }\end{array}$ & $\begin{array}{l}\text { ury. KE } \\
\text { dies in } \\
\text { on (in } \\
\text { previo } \\
\text { down }\end{array}$ & $\begin{array}{l}\text { EG pat } \\
\text { c cardia } \\
\text { DAVID). } \\
\text { us stud } \\
\text {-regulat }\end{array}$ & $\begin{array}{l}\text { hways negatively enr } \\
\text { c tissue. For metabol } \\
\text { The metabolomics st } \\
\text { ly. }{ }^{*} \text {, previous study; }{ }^{*} \\
\text { ed); blue text, commo }\end{array}$ & $\begin{array}{l}\text { riched in animals with car } \\
\text { omics results, the Metabol } \\
\text { tudies are described in thi } \\
*_{*} \text {, this study; red text, com } \\
\text { on to at least two data sets, }\end{array}$ & $\begin{array}{l}\text { rdiac injur } \\
\text { blon pathv } \\
\text { his study a } \\
\text { mmon to } \\
\text { s, but direc }\end{array}$ & $\begin{array}{l}\text { were } \\
\text { ay } \\
\text { d the } \\
\text { least } \\
\text { on }\end{array}$ \\
\hline
\end{tabular}

approved all experimental procedures, which were performed in accordance with the American Physiological Society's guiding principles for research involving animals and adhered to the high standard (best practice) of veterinary care as stipulated in the Guide for Care and Use of Laboratory Animals. Research was conducted in compliance with the Animal Welfare Act, and other Federal statutes and regulations relating to animals and experiments involving animals and adheres to principles stated in the "Guide for Care and Use of Laboratory Animals" (NRC 2011) as prepared by the Committee on Care and Use of Laboratory Animals of the Institute of Laboratory Animal Resources, National Research Council in facilities that are fully accredited by the Association for Assessment and Accreditation of Laboratory Animal Care, International. As previously described [18], male Fischer 344 (F344; n = 48; Charles River Laboratories, Stone Ridge, NY) rats weighing 234-336 g ( 2-3 months old) were used. Briefly, rats were housed under standard laboratory conditions $\left(22^{\circ} \mathrm{C}, 12: 12\right.$ hour light:dark cycle, lights on at 6:00 AM) in an Association for Assessment and Accreditation of Laboratory Animal
Care-accredited facility. A relatively cool housing temperature was chosen to support survival during heat-stress recovery [18], during which chow (Harlan Teklad, LM-485; Madison, WI) and water were provided ad libitum [60]. Rats were implanted with TL11M2-C50-PXT PhysioTel ${ }^{\circledR}$ Multiplus Transmitters (Data Sciences International, St. Paul, MN) to measure core temperature $\left(\mathrm{T}_{\mathrm{c}} ; \pm 0.25^{\circ} \mathrm{C}\right)$, heart rate, and mean arterial pressure $( \pm 3 \mathrm{mmHg})$. Physiological response and temperature regulation after heat stress has been published in recent studies by our laboratories [18,21,59].

All experiments were conducted in conscious, freemoving animals, as previously described [18]. Briefly, rats were placed in a floor-standing incubator (Thermo Scientific, Ashville, NC) set at room temperature (RT, $\left.22^{\circ} \mathrm{C}\right) 24$ hours prior to initiation of heat stress experiments. Non-heated rats were not introduced to the incubator environment. Heat-stress experimentation was initiated after $\mathrm{T}_{\mathrm{c}}$ of the control and experimental rats reached values of approximately $37.3^{\circ} \mathrm{C}$. The following day, food and water were removed from the animal 


\begin{tabular}{|c|c|c|c|c|c|c|c|c|c|}
\hline \multirow{2}{*}{$\begin{array}{c}\text { Transcriptomics }^{*} \\
\text { Pathways enriched in animals with } \\
\text { cardiac injury }\end{array}$} & \multirow[b]{2}{*}{ Count } & \multirow[b]{2}{*}{ P-value } & \multicolumn{3}{|c|}{ Proteomics (iTRAQ)* } & \multicolumn{4}{|c|}{ Metabolomics ${ }^{* *}$} \\
\hline & & & $\begin{array}{l}\text { Pathways enriched in animals } \\
\text { with cardiac injury }\end{array}$ & Count & P-value & $\begin{array}{l}\text { Pathways enriched in } \\
\text { animals with cardiac injury }\end{array}$ & $\begin{array}{l}\text { Complementary KEGG } \\
\text { designation (DAVD) }\end{array}$ & \# identified & \# changed \\
\hline rno04110:Cell cycle & 34 & $1.43 \mathrm{E}-18$ & $\begin{array}{l}\text { rno04612:Antigen processing and } \\
\text { presentation }\end{array}$ & 10 & $2.7 \mathrm{E}-05$ & Fatty acid metabolism & rno00071:Fatty acid metabolism & 4 & 2 \\
\hline mo03030:DNA replication & 16 & 1.51E-09 & $\begin{array}{l}\text { mo } 04610: \text { Complement and } \\
\text { coagulation cascades }\end{array}$ & 7 & $1.6 \mathrm{E}-03$ & $\begin{array}{l}\text { Valine, leucine, and } \\
\text { isoleucine metabolism }\end{array}$ & $\begin{array}{l}\text { mo00280:Valine, leucine and } \\
\text { isoleucine degradation }\end{array}$ & 17 & 16 \\
\hline rno04114:Oocyte meiosis & 19 & $6.24 \mathrm{E}-08$ & $\begin{array}{l}\text { rno04722:Neurotrophin signaling } \\
\text { pathway }\end{array}$ & 9 & $2.0 \mathrm{E}-03$ & Butanoate metabolism & rno00650:Butanoate metabolism & 1 & 1 \\
\hline $\begin{array}{l}\text { mo05322: Systemic lupus } \\
\text { erythematosus }\end{array}$ & 21 & $3.96 \mathrm{E}-07$ & $\begin{array}{l}\text { rno00010: Glycolysis / } \\
\text { Gluconeogenesis }\end{array}$ & 7 & $4.1 \mathrm{E}-03$ & $\begin{array}{c}\text { Glycolysis, } \\
\text { gluconeogenesis, pyruvate } \\
\text { metabolism }\end{array}$ & $\begin{array}{l}\text { rno00010:Glycolysis / } \\
\text { Gluconeogenesis, } \\
\text { rno00620:Pyruvate metabolism }\end{array}$ & 7 & 2 \\
\hline $\begin{array}{l}\text { mo04666:Fc gamma R-mediated } \\
\text { phagocytosis }\end{array}$ & 18 & $2.22 \mathrm{E}-06$ & $\begin{array}{l}\text { mo04810: Regulation of actin } \\
\text { cytoskeleton }\end{array}$ & 11 & $4.5 \mathrm{E}-03$ & $\begin{array}{l}\text { Nucleotide sugars, pentose } \\
\text { metabolism }\end{array}$ & $\begin{array}{l}\text { rno00030:Pentose phosphate } \\
\text { pathway }\end{array}$ & 3 & 2 \\
\hline mo04142:Lysosome & 19 & $2.89 \mathrm{E}-05$ & $\begin{array}{l}\text { rno00030:Pentose phosphate } \\
\text { pathway }\end{array}$ & 4 & $9.0 \mathrm{E}-03$ & Phenylalanine and tyrosine & $\begin{array}{l}\text { rno00360:Phenylalanine } \\
\text { metabolism }\end{array}$ & 16 & 10 \\
\hline $\begin{array}{l}\text { mo04650: Natural killer cell mediated } \\
\text { cytotoxicity }\end{array}$ & 17 & $8.51 \mathrm{E}-05$ & rno03010:Ribosome & 5 & $6.4 \mathrm{E}-02$ & Tryptophan metabolism & rno00380:Tryptophan metabolism & 11 & 9 \\
\hline rno00240:Pyrimidine metabolism & 15 & $2.00 \mathrm{E}-04$ & & & & Purine metabolism & rno00230:Purine metabolism & 5 & 4 \\
\hline $\begin{array}{l}\text { rno04914:Progesterone-mediated } \\
\text { oocyte maturation }\end{array}$ & 14 & $3.85 \mathrm{E}-04$ & & & & Pyrimidine metabolism & rno00240:Pyrimidine metabolism & & \\
\hline mo03010:Ribosome & 14 & 7.41E-04 & & & & $\begin{array}{c}\text { Aminosugars metabolism; } \\
\text { Nucleotide sugars, pentose } \\
\text { metabolism }\end{array}$ & $\begin{array}{l}\text { rno00520:Amino sugar and } \\
\text { nucleotide sugar metabolism }\end{array}$ & 6 & 5 \\
\hline rno03440:Homologous recombination & 7 & 7.97E-04 & & & & & & & \\
\hline $\begin{array}{c}\text { rno04662:B cell receptor signaling } \\
\text { pathway }\end{array}$ & 12 & $9.06 \mathrm{E}-04$ & & & & & & & \\
\hline mo04115:p53 signaling pathway & 12 & 0.0032091 & & & & & & & \\
\hline $\begin{array}{l}\text { rno00520:Amino sugar and nucleotide } \\
\text { sugar metabolism }\end{array}$ & 9 & 0.0032557 & & & & & & & \\
\hline $\begin{array}{l}\text { rno04810: Regulation of actin } \\
\text { cytoskeleton }\end{array}$ & 22 & 0.011394 & & & & & & & \\
\hline $\begin{array}{l}\text { rno04672:Intestinal immune network for } \\
\text { IgA production }\end{array}$ & 8 & 0.0156864 & & & & & & & \\
\hline rno03420:Nucleotide excision repair & 6 & 0.0201 & & & & & & & \\
\hline $\begin{array}{l}\text { rno03430:Mismatch repair } \\
\text { nat-like receptor signaling }\end{array}$ & 5 & 0.0409884 & & & & & & & \\
\hline $\begin{array}{l}\text { rno04620:Toll-like receptor signaling } \\
\text { pathway }\end{array}$ & 10 & 0.045185 & & & & & & & \\
\hline
\end{tabular}

Figure 11 Up-regulated biomarkers predictive of cardiac injury. KEGG pathways positively enriched in animals with cardiac injury were compared across transcriptomics, proteomics, and metabolomics studies in cardiac tissue. For metabolomics results, the Metabolon pathway designation is listed along with the complementary KEGG designation (in DAVID). The metabolomics studies are described in this study and the proteomics and transcriptomics results were described in detail in a previous study. ${ }^{*}$, previous study; ${ }^{*}$, this study; red text, common to at least two data sets, with the same direction in all data sets (up-regulated or down-regulated); blue text, common to at least two data sets, but direction (up-regulated or down-regulated) differs.

cages; the incubator temperature was increased to $37.0 \pm$ $0.2^{\circ} \mathrm{C}$; and the rats were heated until a $\mathrm{T}_{\mathrm{c}}$ of $41.8^{\circ} \mathrm{C}\left(\mathrm{T}_{\mathrm{c}, \mathrm{Max}}\right)$ was reached, at which time they were removed from the incubator, weighed, placed in a new cage, and returned to normal housing temperature $\left(22.0 \pm 0.2^{\circ} \mathrm{C}\right)$. Animals in the 24 and 48 hour cohorts were allowed to recover for the specified time prior to termination. Time-matched control rats experienced the same experimental procedures as the heat-stressed rats, but remained at the normal housing temperature of $22.0^{\circ} \mathrm{C}$ throughout experimentation. Control and experimental animals were provided food and water ad libitum throughout recovery. Plasma, heart, liver, lung, and kidney were harvested at $\mathrm{T}_{\mathrm{c}, \mathrm{Max}}, 24$, or 48 hours with $\mathrm{T}_{\mathrm{c}}$, mean arterial pressure, and heart rate monitored continuously throughout recovery.

\section{Histopathology}

At necropsy, tissues (heart, liver, lung, kidney) were fixed in paraformaldehyde, mounted, sectioned, and stained with hematoxylin and eosin (IHC World, Woodstock, MD). Twenty serial sections were cut per tissue, with three to five sections per slide. Inflammatory or degenerative lesions were graded on a scale of 1 to 5 (grade 1, minimal; grade 5, severe) by a board-certified pathologist (Experimental Pathology Laboratories ${ }^{\oplus}$ [Sterling, VA]).
The results of the histopathological evaluation have been previously published [19].

\section{Metabolomics}

Metabolomic analysis was conducted by Metabolon (Durham, NC). Briefly, frozen plasma samples $(150 \mu \mathrm{l})$ were thawed, and extracts were prepared according to Metabolon's standard protocol, which is designed to remove protein, dislodge small molecules bound to protein or physically trapped in the precipitated protein matrix and recover a wide range of chemically diverse metabolites. Samples were extracted and split into equal parts for analysis on the gas chromatography mass spectrometer and liquid chromatography mass spectrometer platforms. Proprietary software was used to match ions to an inhouse library of standards for metabolite identification and for metabolite quantitation by peak area integration.

\section{Data analysis-metabolomics}

Two-way ANOVA with contrasts was used to analyze the data (See Additional file 1). For all analyses, missing values (if any) were inputted with the observed minimum for that particular compound (inputted values were added after block-normalization). The statistical analyses were performed on natural log-transformed 
data to reduce the effect of any potential outliers in the data. Two-way ANOVA and contrast comparisons were made between the means of each biochemical from the groups and were calculated using either or both of the statistical analysis software programs Array Studio (Omicsoft, Inc.) or ' $R$ ' (R Foundation for Statistical Computing, Vienna, Austria). Statistical cut-offs are typically used to detemine physiological significance in metabolomics studies. Conservative criteria of $\mathrm{p}<0.05$ and $\mathrm{q}<0.1$ are routinely used in metabolomic studies [61], allowing for the identification of significantly altered responses between groups with a false discovery rate of no more than $10 \%$. Because we analyzed a constellation of metabolites in conjunction with biochemical pathways rather than single analytes, we considered $\mathrm{p}<0.05$ significant, regardless of the q value. Using this approach, we could be more inclusive of data that did not meet strict cut-off values, taking both p-value and number of metabolites changing in a given biochemical pathway.

Random forest, a supervised classification technique based on an ensemble of decision trees $[62,63]$ was used to determine the predictive value of multiple biochemicals for both exposure and health effect. For a given decision tree, a random subset of the data with identifying true class information was selected to build the tree ("bootstrap sample" or "training set"), and then the remaining data, the $\mathrm{OOB}$ variables, were passed down the tree to obtain a class prediction for each sample, then repeated thousands of times to produce the forest. The final classification of each sample was determined by computing the class prediction frequency for the OOB variables over the whole forest. Class predictions were compared to the true classes, generating the "OOB error rate" as a measure of prediction accuracy. To determine which variables (biochemicals) made the largest contribution to the classification, a variable importance measure was computed, termed the mean decrease accuracy (MDA). The MDA was determined by randomly permuting a variable, running the observed values through the trees, and then reassessing the prediction accuracy. If a variable is not important, then this procedure had little change in the accuracy of the class prediction (permuting random noise gave random noise). By contrast, if a variable is important to the classification, the prediction accuracy will drop after such a permutation, which we record as the MDA. Thus, the random forest analysis provided an importance rank-ordering of biochemical, and the top 30 biochemicals were reported.

\section{Additional files}

Additional file 1: Is the raw metabolomics data and ANOVA with contrasts for each biochemical analyzed in the study.
Additional file 2: Heat stress persistently increases metabolites controlling pyrimidine and purine degradation. (A) Eighteen biochemicals were identified in the purine and pyrimidine metabolism sub-pathways: at $T_{c, M a x}$ fold changes (heat/control) were significantly increased for 12 biochemicals and significantly decreased for 1 biochemical; at 24 hours, 8 biochemicals were increased and 2 decreased; and at 48 hours, 4 were elevated and 2 decreased in both uninjured and heat-injured animals. (B) Biochemical pathway for pyrimidine degradation. Red, increased over control; green, decreased relative to control; green and red, $p<0.05$; light red, $0.05<p<0.1$

Additional file 3: Acute increase in acetylated biochemicals followed by a decrease at 24 hours and significant differences between uninjured animals and animals with cardiac injury at 48 hours. Of the 13 acetylated biochemicals at $T_{c, M a x}, 12$ were greater in heated animals than controls; at 24 hours, 5 were significantly lower and 2 were significantly higher; at 48 hours in uninjured animals, 3 were significantly higher and 2 were significantly lower; in heat-injured animals, 3 were higher and 5 were lower than controls. Red, fold change significantly higher; green, fold change significantly lower than control $(p<0.05$ by ANOVA); light green, fold change lower compared to controls $(0.05<p<0.1$ by ANOVA).

Additional file 4: Acute increase in sulfated biochemicals followed by a decrease at 24 hours and significant differences between uninjured animals and animals with cardiac injury at $\mathbf{4 8}$ hours. Of the 8 sulfated biochemicals at $T_{c, \text { Max }} 7$ were greater in heated animals than controls; at 24 hours, 4 were significantly lower and none were significantly higher; at 48 hours in uninjured animals, 3 were significantly higher and none were significantly lower; and in heat-injured animals, 4 were higher and none were lower than controls. Red, fold change significantly higher; green, fold change significantly lower than control $(p<0.05$ by ANOVA); light green, fold change slightly lower compared to controls with $0.05<p<0.1$ by ANOVA.

Additional file 5: Altered amino acids and mediators of glycolysis, gluconeogenesis, and pyruvate metabolism after heat stress and recovery. (A) Of the 19 identified amino acids, at $T_{c, \text { Max }} 7$ were significantly lower and 8 were significantly greater; 4 were lower at 24 hours; at 48 hours, 5 were lower and 1 was greater in both uninjured and cardiac-injured animals. Metabolites contributing to glycolysis were initially greater than control, then either returned to normal or were lower than control at 24 and 48 hours. Red, fold change significantly higher; green, fold change significantly lower than control $(p<0.05$ by ANOVA); light green, fold change slightly lower compared to controls; light red, fold change lightly higher than control $(0.05<p<0.1$ by ANOVA). (B) Three amino acids that contribute to the tricarboxylic acid (TCA) cycle for energy production were decreased.

Additional file 6: Increased fatty acid $\beta$-Oxidation modulates acetyl CoA production and cholesterol synthesis in energy production. (A) Metabolic network illustrating how elevations in fatty acid $\beta$-oxidation compensates for compromised TCA cycle, glycolysis, and amino acid metabolism in the production of cellular energy. (B) Alterations in medium chain fatty acids in response to heat stress and recovery. (C) Alterations in biochemicals involved in carnitine metabolism after heat stress. Green cells represent significant decrease. Red cells represent a significant increase in heat-stressed individuals over control cases $(0.05<p<0.10$ heat exposed versus control rat, 2-way ANOVA with contrasts).

Additional file 7: Decrease in bile acids and increase in associated metabolites of bile acid biosynthesis at $T_{c, \text { Max }}$ and 24-48 hours after heat exposure. (A) Tabulation of bile acids and associated metabolites at $T_{C, M a x}$ and 24-48 hours as fold-change from control after heat exposure. (B) Circulation of bile acids. (C) Trend in bile acid and associated metabolites over time after heat stress. Green cells represent significant decrease. Pink reflects a trending increase and light green represents a trending decrease $(0.05<p<0.10$ heat exposed versus control rat, 2 -way ANOVA with contrasts); $*$, $p<0.05$, 2-way ANOVA with contrasts.

Additional file 8: Change in vitamin B6 cofactor activity at $T_{C, \text { Max }}$ and 24-48 hours after heat exposure. (A) Role of vitamin B6

metabolism in amino acid, serotonin/norepinephrine, and sphingolipid synthesis. Trend in (B) pyridoxal and (C) pyridoxate after heat stress. *, $p<0.05,2$-way ANOVA with contrasts. 


\section{Abbreviations}

7-HOCA: 7-a-hydroxy-3-oxo-4-cholestenoate; AA: Amino acid; acetyl CoA: Acetyl coenzyme A; AHB: 2-hydroxybutyrate; AMP: Adenosine monophosphate; ANOVA: Analysis of variance; ATP: Adenosine triphosphate GCS: $\gamma$-glutamyl cysteine synthase; GGT: $\gamma$-glutamyl transferase; GSH: Glutathione; GS: Glutathione synthase; GSSG: Glutathione disulfide, oxidized; KEGG: Kyoto encyclopedia of genes and genomes; MDA: Mean decrease accuracy; NADPH: Nicotinamide adenine dinucleotide phosphate; NO: Nitric oxide; OOB: Out-of-bag; ROS: Reactive oxygenated species; SIRS: System inflammatory response syndrome; $T_{\text {c Max: }}$ Maximum core temperature; TCA: Tricarboxylic acid; USACEHR: US Army Center for Environmental Health Research; USAMRMC: US Army Medical Research and Materiel Command; USARIEM: US Army Research Institute of Environmental Medicine.

\section{Competing interests}

The authors declare that they have no competing interests to declare Research was conducted in compliance with the Animal Welfare Act, and other Federal statutes and regulations relating to animals and experiments involving animals and adheres to principles stated in the "Guide for Care and Use of Laboratory Animals" (NRC 2011) as prepared by the Committee on Care and Use of Laboratory Animals of the Institute of Laboratory Animal Resources, National Research Council in facilities that are fully accredited by the Association for Assessment and Accreditation of Laboratory Animal Care, International. The views, opinions, assertions, and/or findings contained herein are those of the authors and should not be construed as official US Department of Defense or Department of the Army position, policy, or decision, unless so designated by other official documentation. Citations of commercial organizations or trade names in this report do not constitute an official Department of the Army endorsement or approval of the products or services of these organizations. This paper has been approved for public release with unlimited distribution. This research was supported in part by an appointment to the Research Participation Program at the US Army Center for Environmental Health Research (USACEHR) administered by the Oak Ridge Institute for Science and Education through an interagency agreement between USACEHR, the US Department of Energy, and the US Army Medical Research and Materiel Command (USAMRMC). The research was supported by the Military Operational Medicine Research Program, USAMRMC, MD

\section{Authors' contributions}

The initiation and conception of this study involved JDS, JAL, and LRL. CY and JAL provided critical methods review, random forest analyses, hierarchical clustering. DLI (overall) and JDS were responsible for writing the manuscript, which was edited by CY, JAL, and LRL. All authors reviewed the final manuscript.

\section{Acknowledgements}

We would like to thank Dr. Roy Vigneulle (Military Operational Medicine Research Program), CAPT Carroll D. Forcino (Director, Military Operational Medicine Research Program), Dr. David A. Jackson (Director, Pulmonary Health, USACEHR), and LTC Thomas C. Timmes (current Commander, USACEHR) for their programmatic support, encouragement, and insightful discussion. We also thank Dr. Bryan Helwig, J. Ward, S. Dineen, M. Blaha, and R. Duran for access to biofluids and technical support with the rat heat stress experiments. We thank Dr. Andrea Eckhart and Dr. Rob Mohney from Metabolon, Inc., for the report and data analysis of the metabolomics data.

\section{Author details}

${ }^{1}$ The United States Army Center for Environmental Health Research, Environmental Health Program, Bldg. 568 Doughten Drive, Fort Detrick, Frederick, MD 21702-5010, USA. ${ }^{2}$ Biotechnology High Performance Computing Software Applications Institute, Frederick, MD 21702-5010, USA. ${ }^{3}$ Thermal Mountain Medicine Division, US Army Research Institute of Environmental Medicine, Natick, MA 01760-5007, USA.

Received: 25 June 2014 Accepted: 11 December 2014 Published online: 24 December 2014

\section{References}

1. Armed Forces Health Surveillance C: Update: heat injuries, active component, U.S. Armed Forces, 2013. Msmr 2014, 21(3):10-13.
2. Wallace RF, Kriebel D, Punnett L, Wegman DH, Wenger CB, Gardner JW, Gonzalez RR: The effects of continuous hot weather training on risk of exertional heat illness. Med Sci Sports Exerc 2005, 37(1):84-90.

3. Wallace RF, Kriebel D, Punnett L, Wegman DH, Wenger CB, Gardner JW, Kark JA: Risk factors for recruit exertional heat illness by gender and training period. Aviat Space Environ Med 2006, 77(4):415-421.

4. Armed Forces Health Surveillance Center: Update: heat injuries, active component, U.S. Armed Forces, 2011. MSMR 2012, 19(3):14-16.

5. Armed Forces Health Surveillance Center: Update: heat injuries, active component, U.S. Armed Forces, 2012. MSMR 2013, 20(3):17-20.

6. Merrill $C T$, Miller $M$, Steiner $C$ : Hospital stays resulting from excessive heat and cold exposure due to weather conditions in U.S. Community Hospitals, 2005: statistical brief \#55. In: Healthcare Cost and Utilization Project (HCUP) Statistical Briefs. Agency for Health Care Policy and Research (US): Rockville (MD); 2006.

7. United States Army: Army Regulation 40-501: Standards of Medical Fitness. 2011. http://www.armypubs.army.mil/epubs/pdf/r40_501.pdf.

8. Liu ZF, Sun XG, Tang J, Tang YQ, Tong HS, Wen Q, Liu YS, Su L: Intestinal inflammation and tissue injury in response to heat stress and cooling treatment in mice. Mol Med Rep 2011, 4(3):437-443.

9. Leon LR: The thermoregulatory consequences of heat stroke: are cytokines involved? J Therm Biol 2006, 31(1-2):67-81.

10. Leon LR, Helwig BG: Heat stroke: role of the systemic inflammatory response. J Appl Physiol 2010, 109(6):1980-1988.

11. Leon LR, Helwig BG: Role of endotoxin and cytokines in the systemic inflammatory response to heat injury. Front Biosci 2010, 2:916-938.

12. Zeller L, Novack V, Barski L, Jotkowitz A, Almog Y: Exertional heatstroke: clinical characteristics, diagnostic and therapeutic considerations. Eur J Intern Med 2011, 22(3):296-299.

13. Zhou FH, Song Q, Peng ZY, Pan L, Kang HJ, Tang S, Yue H, Liu H, Xie F: Effects of continuous venous-venous hemofiltration on heat stroke patients: a retrospective study. J Trauma-Injury Infect Crit Care 2011, 71(6):1562-1568.

14. Grosman B, Shaik OS, Helwig BG, Leon LR, Doyle FJ: A physiological systems approach to modeling and resetting of mouse thermoregulation under heat stress. J App/ Physiol 2011, 111(3):938-945.

15. Leon LR, Dineen SM, Clarke DC: Early Activation of liver apoptotic signaling pathways during heat stroke recovery in mice. Faseb J 2013 27:1201.7

16. Leon LR, Duran RM, Helwig BG: Complementing heat stroke: activation and amplification of the IL-6 and complement system during heat stroke recovery in F344 rats. Faseb J 2013, 27:1201.6.

17. Leon LR, Eustis HL, Urso ML: Skeletal muscle is a potential source of cytokines during heat stroke recovery in mice. Faseb J 2012, 26:1084.17.

18. Rakesh V, Stallings JD, Helwig BG, Leon LR, Jackson DA, Reifman J: A 3-D mathematical model to identify organ-specific risks in rats during thermal stress. J Appl Physiol 2013, 115(12):1822-1837.

19. Stallings JD, Ippolito DL, Rakesh V, Baer CE, Dennis WE, Helwig BG, Jackson DA, Leon LR, Lewis JA, Reifman J: Patterns of gene expression associated with recovery and injury in heat-stressed rats. BMC Genomics 2014, 15(1):1058.

20. Malmendal A, Overgaard J, Bundy JG, Sorensen JG, Nielsen NC, Loeschcke V, Holmstrup M: Metabolomic profiling of heat stress: hardening and recovery of homeostasis in Drosophila. Am J Physiol Regul Integr Comp Physiol 2006, 291(1):R205-R212.

21. Quinn CM, Duran RM, Audet GN, Charkoudian N, Leon LR: Cardiovascular and thermoregulatory biomarkers of heat stroke severity in a conscious rat model. J Appl Physio/ 2014, 117(9):971-978.

22. Stasolla C, Loukanina N, Yeung EC, Thorpe TA: Alterations in pyrimidine nucleotide metabolism as an early signal during the execution of programmed cell death in tobacco BY-2 cells. J Exp Bot 2004, 55(408):2513-2522.

23. Piskur J, Schnackerz KD, Andersen G, Bjornberg O: Comparative genomics reveals novel biochemical pathways. Trends Genet 2007, 23(8):369-372.

24. Lu Z, Zhang R, Diasio RB: Dihydropyrimidine dehydrogenase activity in human peripheral blood mononuclear cells and liver: population characteristics, newly identified deficient patients, and clinical implication in 5-fluorouracil chemotherapy. Cancer Res 1993, 53(22):5433-5438.

25. van Lenthe $H$, van Kuilenburg $A B$, Ito $T$, Bootsma $A H$, van Cruchten $A$, Wada $Y$, van Gennip AH: Defects in pyrimidine degradation identified by HPLCelectrospray tandem mass spectrometry of urine specimens or urine-soaked filter paper strips. Clin Chem 2000, 46(12):1916-1922. 
26. Kolker S, Okun JG, Horster F, Assmann B, Ahlemeyer B, Kohlmuller D, Exner-Camps S, Mayatepek E, Krieglstein J, Hoffmann GF: 3-Ureidopropionate contributes to the neuropathology of 3-ureidopropionase deficiency and severe propionic aciduria: a hypothesis. J Neurosci Res 2001, 66(4):666-673.

27. Kellogg DL Jr, Crandall CG, Liu Y, Charkoudian N, Johnson JM: Nitric oxide and cutaneous active vasodilation during heat stress in humans. $J$ Appl Physiol 1998, 85(3):824-829.

28. Ray PD, Huang BW, Tsuji Y: Reactive Oxygen Species (ROS) homeostasis and redox regulation in cellular signaling. Cell Signal 2012, 24(5):981-990.

29. Hall DM, Baumgardner KR, Oberley TD, Gisolfi CV: Splanchnic tissues undergo hypoxic stress during whole body hyperthermia. Am J Physiol 1999, 276(5 Pt 1):G1195-G1203.

30. Wu G, Fang YZ, Yang S, Lupton JR, Turner ND: Glutathione metabolism and its implications for health. J Nutr 2004, 134(3):489-492.

31. Lim CL, Wilson G, Brown L, Coombes JS, Mackinnon LT: Pre-existing inflammatory state compromises heat tolerance in rats exposed to heat stress. Am J Physiol Regul Integr Comp Physiol 2007, 292(1):R186-R194.

32. Meaney S, Babiker A, Lutjohann D, Diczfalusy U, Axelson M, Bjorkhem I: On the origin of the cholestenoic acids in human circulation. Steroids 2003, 68(7-8):595-601.

33. Moccand C, Boycheva S, Surriabre P, Tambasco-Studart M, Raschke M, Kaufmann M, Fitzpatrick TB: The pseudoenzyme PDX1.2 boosts vitamin B6 biosynthesis under heat and oxidative stress in Arabidopsis. J Biol Chem 2014, 289(12):8203-8216.

34. Trachootham D, Lu W, Ogasawara MA, Nilsa RD, Huang P: Redox regulation of cell survival. Antioxid Redox Signal 2008, 10(8):1343-1374.

35. Nelson DL, Lehninger AL, Cox MM: Lehninger Principles of Biochemistry. W. H. Freeman and Company New York, NY; 2008.

36. Colleluori DM, Ash DE: Classical and slow-binding inhibitors of human type II arginase. Biochemistry 2001, 40(31):9356-9362.

37. Derave W, Everaert I, Beeckman S, Baguet A: Muscle carnosine metabolism and beta-alanine supplementation in relation to exercise and training. Sports Med 2010, 40(3):247-263.

38. Evans DA: N-acetyltransferase. Pharmacol Ther 1989, 42(2):157-234.

39. Ezaki J, Matsumoto N, Takeda-Ezaki M, Komatsu M, Takahashi K, Hiraoka Y, Taka H, Fujimura T, Takehana K, Yoshida M, Iwata J, Tanida I, Furuya N, Zheng DM, Tada N, Tanaka K, Kominami E, Ueno T: Liver autophagy contributes to the maintenance of blood glucose and amino acid levels. Autophagy 2011, 7(7):727-736.

40. Gathiram P, Wells MT, Brockutne JG, Gaffin SL: Prophylactic corticosteroid increases survival in experimental heat-stroke in primates. Aviat Space Environ Med 1988, 59(4):352-355.

41. Hofmann AF, Molino G, Milanese M, Belforte G: Description and simulation of a physiological pharmacokinetic model for the metabolism and enterohepatic circulation of bile acids in man. cholic acid in healthy man. J Clin Invest 1983, 71(4):1003-1022.

42. Amelio D, Garofalo F, Capria C, Tota B, Imbrogno S: Effects of temperature on the nitric oxide-dependent modulation of the Frank-Starling mechanism: the fish heart as a case study. Comp Biochem Physiol A Mol Integr Physiol 2013, 164(2):356-362.

43. Waagner D, Heckmann LH, Malmendal A, Nielsen NC, Holmstrup M, Bayley $\mathrm{M}$ : Hsp70 expression and metabolite composition in response to short-term thermal changes in Folsomia candida (Collembola). Comp Biochem Physiol A Mol Integr Physiol 2010, 157(2):177-183.

44. Zakir HA, Subbarao GV, Pearse SJ, Gopalakrishnan S, Ito O, Ishikawa T, Kawano N, Nakahara K, Yoshihashi T, Ono H, Yoshida M: Detection, isolation and characterization of a root-exuded compound, methyl 3-(4hydroxyphenyl) propionate, responsible for biological nitrification inhibition by sorghum (Sorghum bicolor). New Phytol 2008, 180(2):442-451.

45. Inoue T, Kobayashi K, Inoguchi T, Sonoda N, Maeda Y, Hirata E, Fujimura Y, Miura D, Hirano K, Takayanagi R: Downregulation of adipose triglyceride lipase in the heart aggravates diabetic cardiomyopathy in $\mathrm{db} / \mathrm{db}$ mice. Biochem Biophys Res Commun 2013, 438(1):224-229.

46. Kasiganesan H, Wright GL, Chiacchio MA, Gumina G: Novel I-adenosine analogs as cardioprotective agents. Bioorg Med Chem 2009, 17(14):5347-5352.

47. Hecker PA, Leopold JA, Gupte SA, Recchia FA, Stanley WC: Impact of glucose-6-phosphate dehydrogenase deficiency on the pathophysiology of cardiovascular disease. Am J Physiol Heart Circ Physiol 2013, 304(4):H491-H500.
48. Beyoglu D, Imbeaud S, Maurhofer O, Bioulac-Sage P, Zucman-Rossi J, Dufour $J F$, Idle JR: Tissue metabolomics of hepatocellular carcinoma: tumor energy metabolism and the role of transcriptomic classification. Hepatology 2013, 58(1):229-238

49. Sharma S, Aramburo A, Rafikov R, Sun X, Kumar S, Oishi PE, Datar SA, Raff G, Xoinis K, Kalkan G, Fratz S, Fineman JR, Black SM: L-carnitine preserves endothelial function in a lamb model of increased pulmonary blood flow. Pediatr Res 2013, 74(1):39-47.

50. Strauss M, Anselmi G, Hermoso T, Tejero F: Carnitine promotes heat shock protein synthesis in adriamycin-induced cardiomyopathy in a neonatal rat experimental model. J Mol Cell Cardiol 1998, 30(11):2319-2325.

51. Sun X, Sharma S, Fratz S, Kumar S, Rafikov R, Aggarwal S, Rafikova O, Lu Q, Burns T, Dasarathy S, Wright J, Schreiber C, Radman M, Fineman JR, Black SM: Disruption of endothelial cell mitochondrial bioenergetics in lambs with increased pulmonary blood flow. Antioxid Redox Signal 2013, 18(14):1739-1752.

52. Dai BH, Geng L, Wang Y, Sui CJ, Xie F, Shen RX, Shen WF, Yang JM: microRNA-199a-5p protects hepatocytes from bile acid-induced sustained endoplasmic reticulum stress. Cell Death Dis 2013, 4:e604.

53. Ejiri S, Eguchi Y, Kishida A, Ishigami F, Kurumi Y, Tani T, Kodama M: Cellular distribution of thrombomodulin as an early marker for warm ischemic liver injury in porcine liver transplantation: protective effect of prostaglandin 12 analogue and tauroursodeoxycholic acid. Transplantation 2001, 71(6):721-726.

54. Ferreira M, Coxito PM, Sardao VA, Palmeira CM, Oliveira PJ: Bile acids are toxic for isolated cardiac mitochondria: a possible cause for hepatic-derived cardiomyopathies? Cardiovasc Toxicol 2005, 5(1):63-73.

55. Gao X, Fu L, Xiao M, Xu C, Sun L, Zhang T, Zheng F, Mei C: The nephroprotective effect of tauroursodeoxycholic acid on ischaemia/ reperfusion-induced acute kidney injury by inhibiting endoplasmic reticulum stress. Basic Clin Pharmacol Toxicol 2012, 111(1):14-23.

56. Panda S, Biswas S, Kar A: Trigonelline isolated from fenugreek seed protects against isoproterenol-induced myocardial injury through down-regulation of Hsp27 and alphaB-crystallin. Nutrition 2013, 29(11-12):1395-1403.

57. Stott WT, Kleinert KM: Effect of diisopropanolamine upon choline uptake and phospholipid synthesis in Chinese hamster ovary cells. Food Chem Toxicol 2008, 46(2):761-766

58. Khatri P, Sirota M, Butte AJ: Ten years of pathway analysis: current approaches and outstanding challenges. PLoS Comput Biol 2012, 8(2):e1002375.

59. Rakesh V, Stallings JD, Reifman J: A virtual rat for simulating environmental and exertional heat stress. J App/ Physiol 2014, 117(11):1278-1286.

60. Davies B, Morris T: Physiological parameters in laboratory animals and humans. Pharm Res 1993, 10(7):1093-1095.

61. Bartel J, Krumsiek J, Theis FJ: Statistical methods for the analysis of high-throughput metabolomics data. Comput Struct Biotechnol J 2013, 4:e201301009.

62. Breiman L: Using iterated bagging to debias regressions. Mach Learn 2001, 45(3):261-277.

63. Goldstein BA, Hubbard AE, Cutler A, Barcellos LF: An application of random forests to a genome-wide association dataset: methodological considerations \& new findings. BMC Genet 2010, 11:49.

\section{Submit your next manuscript to BioMed Central and take full advantage of:}

- Convenient online submission

- Thorough peer review

- No space constraints or color figure charges

- Immediate publication on acceptance

- Inclusion in PubMed, CAS, Scopus and Google Scholar

- Research which is freely available for redistribution 